\title{
Systematic reduction of complex tropospheric chemical mechanisms, Part I: sensitivity and time-scale analyses
}

\author{
L. E. Whitehouse ${ }^{1}$, A. S. Tomlin ${ }^{1}$, and M. J. Pilling ${ }^{2}$ \\ ${ }^{1}$ Energy and Resources Research Institute, University of Leeds, Leeds LS2 9JT, UK \\ ${ }^{2}$ School of Chemistry, University of Leeds, Leeds LS2 9JT, UK
}

Received: 1 April 2004 - Published in Atmos. Chem. Phys. Discuss.: 8 July 2004

Revised: 29 September 2004 - Accepted: 30 September 2004 - Published: 5 October 2004

\begin{abstract}
Explicit mechanisms describing the complex degradation pathways of atmospheric volatile organic compounds (VOCs) are important, since they allow the study of the contribution of individual VOCS to secondary pollutant formation. They are computationally expensive to solve however, since they contain large numbers of species and a wide range of time-scales causing stiffness in the resulting equation systems. This paper and the following companion paper describe the application of systematic and automated methods for reducing such complex mechanisms, whilst maintaining the accuracy of the model with respect to important species and features. The methods are demonstrated via application to version 2 of the Leeds Master Chemical Mechanism. The methods of Jacobian analysis and overall rate sensitivity analysis proved to be efficient and capable of removing the majority of redundant reactions and species in the scheme across a wide range of conditions relevant to the polluted troposphere. The application of principal component analysis of the rate sensitivity matrix was computationally expensive due to its use of the decomposition of very large matrices, and did not produce significant reduction over and above the other sensitivity methods. The use of the quasi-steady state approximation (QSSA) proved to be an extremely successful method of removing the fast time-scales within the system, as demonstrated by a local perturbation analysis at each stage of reduction. QSSA species were automatically selected via the calculation of instantaneous QSSA errors based on user-selected tolerances. The application of the QSSA led to the removal of a large number of alkoxy radicals and excited Criegee bi-radicals via reaction lumping. The resulting reduced mechanism was shown to reproduce the concentration profiles of the important species selected from the full mechanism over a wide range of conditions, including those outside of which the reduced mechanism was
\end{abstract}

Correspondence to: A. S. Tomlin

(fueast@leeds.ac.uk) generated. As a result of a reduction in the number of species in the scheme of a factor of 2 , and a reduction in stiffness, the computational time required for simulations was reduced by a factor of 4 when compared to the full scheme.

\section{Introduction}

A large number of volatile organic compounds (VOCs) contribute to the production of secondary pollutants in the lower atmosphere. The relative contribution of VOCs to the formation of specific secondary pollutants varies from one compound to another by virtue of differences in their reactivity and structure. Explicit mechanisms describing complex sets of degradation pathways are therefore required in order to evaluate the individual contributions of each VOC to secondary pollutant generation. The description of such complex pathways however, requires a large amount of mechanistic detail and leads to chemical schemes with very large numbers of species and reactions. Such explicit mechanisms are not easily employed within complex 3-D atmospheric dispersion models, particularly within the Eulerian framework, since large numbers of coupled species within each grid cell are computationally extremely expensive to solve. In recent years however, a number of techniques have been developed which aim to reduce large explicit mechanisms to more compact chemical representations in a systematic way, such that the accuracy of the reduced scheme is not substantially degraded when compared to the full scheme. Such methods include species lumping, sensitivity analysis, computational singular perturbation theory, low dimensional manifolds and repromodelling (Tomlin et al., 1998; Lam and Goussis, 1988; Maas and Pope, 1992; Turányi et al., 1993).

The systematic application of a number of these techniques may lead to chemical representations that accurately describe the behaviour predicted by fully explicit schemes, but at a reduced computational cost. For extremely complex 
schemes an additional requirement is that such reduction methods can be applied in an automatic way according to well defined principles. This paper, and the following companion paper, attempt to present such a systematic and automated reduction procedure that may be applied to any explicit atmospheric chemical mechanism. The procedure involves the application of a range of sensitivity analysis techniques followed by the lumping of the reaction mechanism based on the underlying chemical timescales. The methods are illustrated via application to version 2 of the Master Chemical Mechanism MCM, (Jenkin et al., 1997). Section 2 of the paper gives a brief introduction to the MCM. Section 3 describes the formulation of the trajectory simulations that are used to define the conditions under which the reduced mechanisms have been derived and compared against the full mechanism. Section 4 describes the application of sensitivity based methods for reduction of the mechanism and Sect. 5 the application of time-scale based methods such as the Quasi-Steady State Approximation (QSSA). In Sect. 6 the application of perturbation methods for assessing the number of variables required to represent the dynamics of the full system is presented, along with an analysis of the numbers of slow, intermediate and fast variables at each stage of the reduction. In Sect. 7, comparisons between the full and reduced mechanisms are shown for a range of conditions. In Sect. 8, a discussion of the methods and results is given. Final conclusions are drawn in Sect. 9.

\section{The master chemical mechanism}

The Protocol for the Master Chemical Mechanism (MCM) was developed in Jenkin et al. (1997) for investigating the production of ozone from a large range of VOCs. The mechanism was designed to describe the complete tropospheric oxidation of 124 VOCs and to accommodate a full range of VOC: $\mathrm{NO}_{\mathrm{x}}$ ratios. The VOCs which are degraded in this mechanism were selected on the basis of available emissions data and provide approximately $91 \%$ mass coverage of the emissions of uniquely identifiable chemical species (Rudd, 1995). The MCM was designed to be applied in areas where detailed chemistry is required, e.g. in predicting the generation of intermediates such as multifunctional carbonyls, hydroperoxides and nitrates etc. for which field data are now becoming available. The protocol is summarised in Fig. 1.

The methodology is to start with the compounds with the lowest number of carbon atoms, e.g. $\mathrm{CH}_{4}, \mathrm{CH}_{3} \mathrm{OH}, \mathrm{HCHO}$, and work upwards. Each VOC is treated separately and its degradation is continued until a species is formed which has already appeared and been treated in an earlier (low $\mathrm{C}$ number) VOC scheme. The reactions included in this protocol are classified as $\mathrm{OH}$ radical initiation reactions for all VOCs together with $\mathrm{O}_{3}$ initiation reactions, $\mathrm{NO}_{3}$ radical initiation reactions and initiation by photolysis where appropriate. Reaction of organic radicals, peroxy radicals, oxy rad- icals, Criegee bi-radicals and reactions of degradation products are also included, see Fig. 1.

The detailed kinetic modelling of these chemically complex processes requires the construction of a comprehensive mechanism comprising all the possible elementary reactions including the respective rate coefficients. The availability of kinetic and mechanistic data relevant to the oxidation of VOCs has increased significantly in recent years and various aspects of the tropospheric chemistry of organic compounds have been reviewed extensively in Atkinson (1990, 1994); Roberts (1990); Lightfoot et al. (1992). This database can be used to construct detailed degradation schemes for a range of organic compounds. To ensure a consistent approach in developing the mechanisms, a set of detailed criteria for defining the degradation schemes has been formulated by drawing upon all current sources of information. Experimental rate data are used where possible, and where no data are available comparison with similar compounds is used. Failing this, well founded assumptions, approximations and estimations are made based on this experimental database.

The rate coefficients for reactions of $\mathrm{OH}$ with various organic compounds were taken from either the IUPAC kinetic evaluations in Atkinson et al. (1992) or from Atkinson (1994, 1989). In the absence of experimental data, rate coefficients appropriate to $298 \mathrm{~K}$ were estimated by the Structure Activity Relationship (SAR) method devised by Atkinson in Atkinson (1987) and updated in Kwok and Atkinson (1995) for alkanes, carbonyls, alcohols, ethers and chlorinated hydrocarbons, and by the method from Peeters et al. (1994) for alkenes and dienes. In order to reduce the complexity of the mechanism, a surrogate species $\mathrm{RO}_{2}$ has been defined in the $\mathrm{MCM}$ as the sum of all peroxy radicals. The overall rate coefficients for the reactions of individual peroxy radicals with $\mathrm{NO}, \mathrm{NO}_{2}, \mathrm{NO}_{3}, \mathrm{HO}_{2}$ and the permutation reactions between $\mathrm{RO}_{2} \mathrm{~s}$ were evaluated based on experimental data in Lightfoot et al. (1992). Parametric forms are based on those recommended in Jenkin et al. (1997).

Photolysis rate parameters depend on the solar zenith angle. Based on two parameter calculations made in Hough (1988) for clear sky conditions at an altitude of $0.5 \mathrm{~km}$, a formula was determined in Jenkin et al. (1997) to express the variation of the photolysis rate $J$ with the solar zenith angle $\theta$,

$J=l(\cos \theta)^{m} e^{-n \sec \theta}$

where the three parameters $(l, m, n)$ are optimised by fitting measured data (Jenkin et al., 1997). The solar zenith angle, $\theta$, is calculated as a function of the time of day (represented by the local hour angle, LHA), the time of year (represented by the solar declination angle DEC) and the latitude (LAT) (Derwent and Jenkin, 1990):

$$
\begin{array}{r}
\cos (\theta)=\cos (\mathrm{LHA}) \cos (\mathrm{DEC}) \cos (\mathrm{LAT}) \\
+\sin (\mathrm{DEC})+\sin (\mathrm{LAT}) .
\end{array}
$$




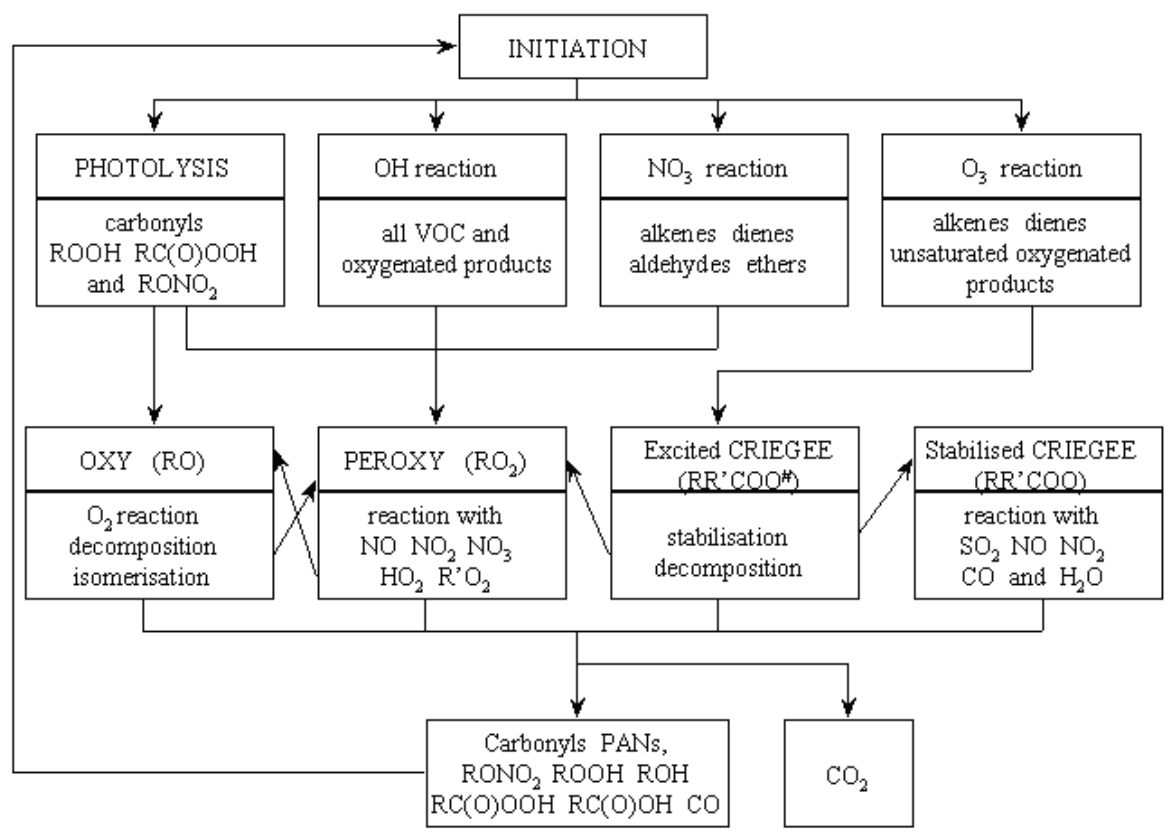

Fig. 1. The mechanism development of the tropospheric degradation of the VOCs.

Initial studies of ozone formation, in comparison with a previous chemical mechanism (Derwent et al., 1996), were found to give good agreement. More recent studies have also been carried out by evaluating the MCM against smog chamber and observational data in Jenkin et al. (1999). The overall results are very encouraging, and problem areas have been identified, which provide the impetus for further reviews and updates (Pilling et al., 1999).

The fully explicit MCMv2.0 was chosen for the investigation of reduction techniques in this work. The full mechanism contains 3487 species and 10763 reactions. The aim is to generate a set of mechanisms of different levels of reduction, and therefore different accuracies, to enable a choice of mechanisms available to potential users depending on the level of detail and accuracy required. Clearly the larger the mechanism the more computationally expensive it will be to solve. At the culmination of the reductions a comparison of accuracy and computational speed will be presented for each reduced mechanism.

Since the application of reduction methods in this work, an updated version of the MCMv3. has been developed. Major improvements have been made to the reaction mechanisms of the aromatic compounds (Saunders et al., 2003; Jenkin et al., 2003). These are an important class of ozone producing VOCs. Revision of the photolysis rates has been carried out, especially with respect to multifunctional carbonyl products formed in the aromatic systems and the MCM has been expanded to include the important biogenic compounds $\alpha$ and $\beta$ pinene. Although the work in this project was carried out on MCM v2.0, it is still relevant as the advances made in the new version are mainly in the aromatics with which we were not greatly concerned in this instance. Furthermore this work presents the development of systematic methodologies that can be generally and automatically applied and would therefore be relevant to the reduction of other mechanisms including any updated versions of the MCM.

\section{Simulation conditions for mechanism reduction}

\subsection{Design of scenarios}

Due to the large number of variables in many comprehensive mechanisms it is not usually possible to apply reduction strategies within a full three dimensional Eulerian framework since the computational expense of the using the full model would be too large. A common strategy is therefore to devise a zero dimensional, well mixed, fixed box model which attempts to cover the main concentration regimes that would be encountered within a full reactive transport code by calculating a broad range of emissions and/or initial conditions. For the purposes of applying the reduction methods, the MCM has therefore been studied within many such box model simulations, since this is computationally less expensive than a full grid calculation. The aim has been to achieve a range of concentrations of major species that are encountered in polluted tropospheric UK conditions. The concentration ranges of major species from all trajectories used in the reduction procedure have been compared with measured concentrations from UK urban monitoring sites to ensure that they are representative. Since the reduction analysis used is 
Table 1. Emissions fractions for given sources in the UK and West Midlands, RT - Road Transport, SU - Solvent Use, IP - Industry and Processes, FF - Fossil Fuel Distribution, DC - Domestic Combustion, PG - Power Generation, specifically power stations, OT Other, NA - Natural.

\begin{tabular}{llll}
\hline $\begin{array}{l}\text { Emission } \\
\text { source }\end{array}$ & $\begin{array}{l}\text { Category total } \\
\mathrm{kt} \mathrm{C} \mathrm{yr}^{-1}\end{array}$ & & Category $\%$ \\
& $\mathrm{UK}$ & $\mathrm{UK}$ & West Midlands \\
\hline RT & 527.3 & 26.9 & 45.9 \\
SU & 532.4 & 27.2 & 49.1 \\
IP & 298.3 & 15.2 & 0.3 \\
FF & 298.2 & 15.2 & 2.5 \\
DC & 40.1 & 2.1 & 0.5 \\
PG & 6.4 & $3.3 \times 10^{-3}$ & 0.0 \\
OT & 77.6 & 4.0 & 1.0 \\
NA & 178 & 9.1 & 0.7 \\
\hline total & 1958.3 & 100 & 100 \\
\hline
\end{tabular}

entirely local, it is in fact only the local concentrations of all species that are important and not the model from which they are generated. The intention was therefore to keep the box model as simple as possible whilst generating a range of concentrations typical of UK urban environments.

The chemical rate equations of the system can be represented in the form

$\frac{d c_{i}}{d t}=f(\boldsymbol{c}, \boldsymbol{k})+E_{i}$

where $\boldsymbol{c}$ is the vector of the species concentrations, $\boldsymbol{k}$ is the rate coefficient vector and $E_{i}$ is the emission into the box for species $i$. The range of concentrations chosen to represent a typical urban atmosphere were taken from measurements in Birmingham during the PUMA campaign (PUMA, 2001), from Middlesbrough using data from the AURN site (AEATENV) and from the AURN site at Marylbone Road in London. From these data it was assumed that total $\mathrm{NO}_{\mathrm{x}}$ varies between $0 \mathrm{ppb}$ and $500 \mathrm{ppb}$, with a $\mathrm{VOC} / \mathrm{NO}_{\mathrm{x}}$ ratio within the range 0.25 to 8 . A range of 33 box model scenarios was designed with appropriate emissions and initial conditions to simulate this range of concentrations. The full set of 94 trajectories was obtained by using three different initial conditions for ozone. The selected conditions of each trajectory are given in Table 7 in Appendix 1.

\subsection{Selection of emissions scenarios}

Using data from the National Atmospheric Emissions Inventory (NAEI) and the West Midlands Inventory, relative emissions factors for VOCs in the mechanism have been calculated for a typical urban region. Each database contains eight source categories to which all emissions are ascribed. The percentage emission fractions for all the primary VOCs in the MCM for the National Emissions Inventory for the UK
Table 2. Initial concentrations for species in MCM at $298 \mathrm{~K}$.

\begin{tabular}{lll}
\hline Species & $\begin{array}{l}\text { initial concentration } \\
\left(\text { molecules } \mathrm{cm}^{-3}\right)\end{array}$ & $(\mathrm{ppb})$ \\
\hline $\mathrm{NO}$ & $1 \times 10^{9}$ & $4.13 \times 10^{-2}$ \\
$\mathrm{NO}_{2}$ & $1 \times 10^{9}$ & $4.13 \times 10^{-2}$ \\
$\mathrm{HCHO}$ & $1 \times 10^{11}$ & 4.13 \\
\hline
\end{tabular}

were obtained from NAEI (2000) for the different categories shown in Table 1. The relative sectors show different contributions for urban areas such as the West Midlands compared to the UK totals. In urban areas road transport has a much higher contribution than within the national average. Sources from solvent use are also higher in the West Midlands than the national average, with industry and process sources much lower.

Unfortunately, the data for emissions for speciated VOCs was only available for the UK inventory, so it was necessary to use the comparison between the relative amount for each emissions source to calculate the contributions in the West Midlands for each VOC within the MCM. Each UK total per emission source for a species was multiplied by the relative contribution of that source in the West Midlands. This gives the relative contribution of that species for a particular emission source category in the West Midlands. If these are summed across all emissions sources the total relative emission per species can be calculated for the West Midlands. This means that the total relative contribution of a VOC to the total emission is given by:

$$
\begin{aligned}
& \left(\sum_{\text {emissions sources }}\right. \text { West Midland rel. contribution } \\
& \times \text { rel. national contribution of source) . }
\end{aligned}
$$

The full set of emissions factors used for the MCM box model simulations resulting from this procedure are given in Tables 8 and 9 in Appendix 1. Total VOC and $\mathrm{NO}_{\mathrm{x}}$ emissions are selected for each trajectory and these are given in Table 7. These values were selected in order to provide the range of VOC: $\mathrm{NO}_{\mathrm{x}}$ required to present an appropriate span of conditions found in UK urban areas. The VOC: $\mathrm{NO}_{\mathrm{x}}$ ratios shown in Table 7 represent those obtained under maximum $\mathrm{NO}_{\mathrm{x}}$ concentrations for the trajectory and are therefore indicative of the types of emissions scenario represented by each trajectory. The emissions rates chosen were designed to achieve these ratios and are maintained throughout the simulation. In Table 7 it can be seen that some trajectory conditions do not have a number and were therefore not used in this investigation. Some of the maximum values generated by these trajectories lie outside those limits prescribed earlier and were therefore not used within the mechanism reduction strategy. Table 2 gives the initial conditions of those species with a non-zero initial concentration. 


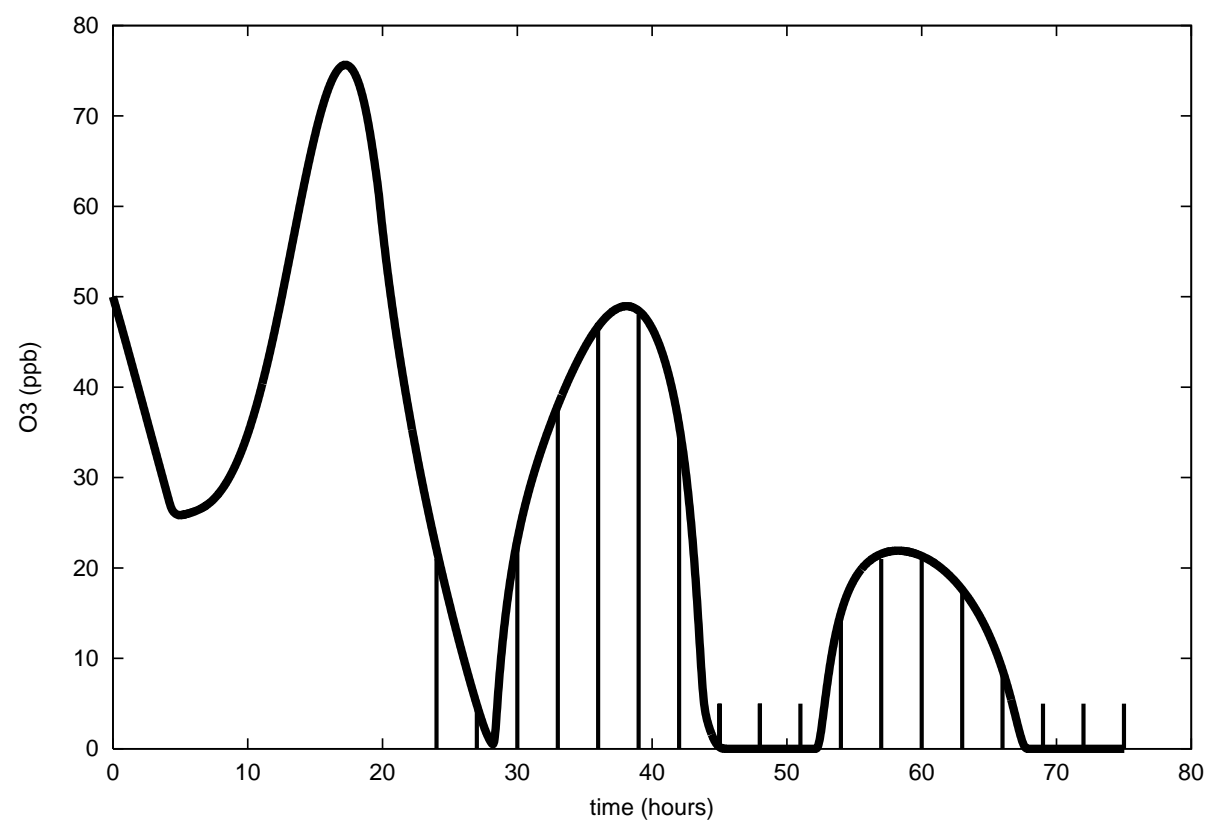

Fig. 2. Example trajectory indicating time-points used during mechanism reduction - the vertical lines indicate the locations of the selected time-points for all trajectories.

\subsection{Simulation conditions}

Each simulation was run for a 72 hour period starting at midnight with variations in both temperature and solar flux for a typical diurnal cycle in July at a latitude of $50^{\circ} \mathrm{N}$. The box was assumed to be well mixed and at atmospheric pressure. The temperature variation throughout the day was given by

$T=289.86+8.3 \sin \left(\left(7.2722 \times 10^{-5} t-1.9635\right)\right) K$

where $t$ is the time of day in seconds (Heard et al., 1998). The numerical integration method used was the variable theta method that forms part of the Sprint package (Berzins and Furzland, 1985). The integration time is determined through the control of numerical error and therefore depends on the local solution gradient. The periods of sunrise and sunset therefore tend to lead to much smaller time-steps. The Sprint package was chosen due to its high reported accuracy for the solution of large systems of stiff ordinary differential equations and its ability to solve coupled algebraic, differential equations required to test the QSSA method.

The trajectories selected all show a characteristic diurnal variation in ozone concentrations associated with species formed as result of photolytically initiated reactions. At sunset the reduction in photolytic activity and the reaction of ozone with NO leads to a reduction in the concentration of ozone. Such low ozone concentrations would be typical of polluted road-side conditions where high emissions of NO relative to $\mathrm{NO}_{2}$ would occur from engine sources.

Suitable time-points from the trajectories described above were used during the reduction procedure. These were se- lected over the second and third days of the simulations following the build up of intermediate compounds. Points were taken every three hours from the $24 \mathrm{~h}$ point until the end of the third day.

This provides good data coverage over areas of swift growth and decay, but also does not neglect the night-time areas as shown in Fig. 2.

Three trajectories have been chosen to plot at each reduction stage so that the deviation in accuracy from the full scheme can be seen. These trajectories were selected as ones which typically represent realistic urban conditions with maximum ozone levels of less than $100 \mathrm{ppb}$ and a variety of $\mathrm{NO}_{\mathrm{x}}$ conditions from $300 \mathrm{ppb}$ down to around $7 \mathrm{ppb}$.

\subsection{Selection of important species}

The following species were determined to be of interest and so were designated important species which should be accurately represented by the reduced schemes: $\mathrm{O}_{3}, \mathrm{NO}, \mathrm{NO}_{2}$, $\mathrm{HNO}_{3}, \mathrm{NO}_{3}, \mathrm{HONO}, \mathrm{HNO}_{3}, \mathrm{HO}_{2} \mathrm{NO}_{2}, \mathrm{HCHO}, \mathrm{OH}$ and the sum of all peroxy acyl nitrate (PAN) species, examined as total PAN. $\mathrm{O}_{3}, \mathrm{NO}_{\mathrm{x}}$ and total PAN were selected as they are major pollutants in urban environments and have a significant impact on human health and the environment. The remaining species are included as they are known to have extensive involvement in the mechanisms of the three major species or other important tropospheric processes. 


\section{The application of sensitivity analysis}

Mechanism reduction techniques are well suited to situations where a large mechanism such as the MCM is to be applied to a specific set of environmental conditions. Reduction of the mechanism requires the identification of a smaller subset of reactions that can describe the chemistry of the mechanism to within a prescribed accuracy and therefore results in a less computationally expensive system. It is therefore a logical first step to reduce the number of chemical species, as the majority of computing time is spent solving their rate equations. Semi-automatic techniques based on sensitivity analysis have been used to derive greatly simplified chemical schemes which accurately represent the behaviour of chosen key species (Turányi, 1990b; Tomlin et al., 1992; Turányi et al., 1993). As a result of the application of these techniques, redundant reactions and species can be removed from the mechanism as described in Tomlin et al. (1998); Heard et al. (1998); Zeng et al. (1997). In Heard et al. (1998) a number of systematic reduction techniques were applied to CBM-EX, an extended version of the carbon bond mechanism in order to ascertain their applicability to atmospheric systems. Similar methods were applied in Zeng et al. (1997) for the reduction of a subset of the MCM describing the tropospheric oxidation of butane. The systematic reduction of large kinetic systems using automated and slightly modified versions of such techniques will be briefly described in this section and subsequently applied to MCMv2.0.

\subsection{Identification of redundant species}

The aim of most kinetic modelling studies is to describe properly the concentration changes of certain species or key reaction features which are considered important (Turányi et al., 1993). The reduced model must generate values for the important species and features which are in agreement with those generated by the full scheme within a specified accuracy. It is necessary to identify the redundant species which can be excluded from the model, and necessary species which must be included in order to produce accurate results for the important species. The necessary species will be coupled to the important ones by significant reactions. Redundant species will be those which are not coupled in any significant way to the set of important and necessary species and so can be excluded from the model with only negligible effects on the important concentrations both directly and indirectly.

Redundant species can be identified via the investigation of the system Jacobian (Turányi, 1990b). A change in the concentration of a species affects the rates of those reactions in which this species is a reactant. A direct effect will be a change in the concentration in those species which are reactants or products of those reactions. The primary concentration changes then may cause a change in the concentration of other species. A species may be considered redundant if its concentration change has no significant effect on the rate of production of important species. Following operator splitting the chemical rate equations form a system of ODEs:

$\frac{d \boldsymbol{c}}{d t}=f(\boldsymbol{c}, \boldsymbol{k}), \quad \boldsymbol{c}(0)=\boldsymbol{c}_{0}$,

where $c$ is the $n$ dimensional species concentration vector and $\boldsymbol{k}$ is the vector of rate parameters. The influence of the change of concentration of species $i$ on the rate of production of an $\mathrm{N}$-membered group of important species is given by the sum of squares of normalised Jacobian elements,

$B_{i}=\sum_{n=1}^{N}\left(\frac{\partial \ln f_{n}}{\partial \ln c_{i}}\right)^{2}$

The higher the $B_{i}$ value of a species, the greater its direct effect on important species. However, necessary species influence the concentration of important species through indirect coupling. Thus, the group of necessary species must be identified using an iterative method, where the highest ranked species on the basis of the $B_{i}$ values are also considered in the summation for each subsequent iteration. Usually, a suitable threshold is chosen, often where a large gap in the spectrum exists, and the procedure repeated until no new species are admitted into the $N$-membered group. The redundant species are those which are not included in the summation after the final iteration at any of the selected reaction times. The major problem with this procedure is that the threshold limits for the $B_{i}$ values are somewhat arbitrary for cases where no obvious gaps exist. For a complex mechanism like the MCM, with several thousand initial species, this problem arises and a continuous spectrum of $B_{i}$ values is found for most conditions. Some modifications to previous methods were therefore required for reduction of the MCM.

In this work, after each iteration the top 10 species were added to the group of important species. The iterations were continued until there were 1500 species in the group. A range of values was tested and 1500 was selected as a value at which a large number of species could be removed whilst continuing to preserve the accuracy of the model. The method therefore allows the identification of the most important 1500 species at each time point. The procedure was carried out at each of the chosen time-points for each trajectory. When this was complete all those species occurring in any of the lists of 1500 species were added to a master list of necessary species. Ultimately more than 1500 species were retained since any species which was important at even just one time-point of one trajectory must be kept in order to preserve the accuracy of the system over the wide range of trajectories selected. At this stage 396 species and 1224 reactions were removed from the mechanism. This reduced model will be referred to as Stage 1 in the following discussion. 
4.2 Identifying redundant reactions through local rate sensitivities

In Turányi et al. (1989) a method was developed to identify redundant reactions based on the investigation of local rate sensitivities. The analysis measures the effect of a perturbation in a rate parameter on the rate of production of a necessary or important species (Heard et al., 1998). In Turányi et al. (1989) it has been shown that in such a localised firstorder approach, the normalised rate sensitivities can be more efficiently used than concentration sensitivities, as algebraic expressions for the elements of the rate sensitivity matrix can be defined. The normalised rate sensitivity matrix $F_{i j}$ can be calculated from:

$F_{i j}=\frac{k_{j}}{f_{i}} \frac{\partial f_{i}}{\partial k_{j}}$,

where $f_{i}$ can be defined as,

$f_{i}=\sum_{j} v_{i j} R_{j}$

Here $v_{i j}$ is the stoichiometric coefficient of species $i$ in reaction $j$ and $R_{j}$ is the rate of that reaction. Hence

$F_{i j}=\frac{v_{i j} R_{j}}{f_{i}}$.

\subsection{Principal component analysis}

The sensitivity matrix generates a very large amount of information that must be evaluated at many time-steps, as it is essentially a local calculation. Consequently, useful information is obtained from $F_{i j}$ using either overall sensitivities or principal component analysis, which calculates the effect that changing a parameter such as a rate constant has on the concentration or rate of production of several or groups of species (Vajda et al., 1985; Tomlin et al., 1998). In this way principal component analysis provides a method for selecting a reaction set from the sensitivity data by examining reaction interactions and eliminating groups of reactions which do not significantly affect the concentration of important or necessary species rather than individual ones. Principal component analysis is achieved via the eigenvalue/eigenvector decomposition of the matrix $\tilde{\mathbf{F}}^{T} \tilde{\mathbf{F}}$. The eigenvectors reveal the related parameters, and the corresponding eigenvalues express the weight of these parameter groups (Vajda et al., 1985). This is usually carried out on a sub-matrix related to the important and necessary species rather than all the species of the mechanism. Reactions with large eigenvector coefficients associated with large eigenvalues are the most important reactions in the mechanism. By defining threshold values for significant magnitudes of both the eigenvalues and eigenvectors, the method provides an automatic way of deciding which of the reactions can be eliminated from the reduced model (Heard et al., 1998). Principal component analysis therefore provides a way of summarising the information contained in the sensitivity matrix, and at the same time reveals connections between parameters which would not be apparent when studying the original sensitivity matrix. The number of species included in the mechanism can also be reduced but only if the elimination of reactions causes a particular species to also be eliminated. This is why for mechanism reduction the principal component analysis of the reaction system should be performed in tandem with the sensitivity analysis used to identify important and necessary species within the scheme (Tomlin et al., 1998).

\subsection{Application of rate sensitivity analysis to the MCM}

\subsubsection{The use of overall sensitivities}

The computational requirements of interpreting the sensitivity information using principal component analysis were found to be high due the costs of manipulating a $9839 \times 9839$ matrix. In order to overcome this problem the use of an overall sensitivity measure was used prior to the application of principal components. In addition, it was necessary to exploit the sparsity of the system. It was possible via initial investigation of the matrix to determine the number of nonzero entries of the rate sensitivity matrix. These were marked in such a way that subsequent use of the matrix accessed only the entries with non-zero values. In addition, the matrix terms were normalised individually rather than normalising the Jacobian, in order to reduce the computational time of the method. Therefore the overall sensitivity measure is given by:

$F_{j}=\sum_{i}\left(\frac{\partial f_{i}}{\partial k_{j}} \frac{k_{j}}{f_{i}}\right)^{2}$.

The user then selects a threshold and any reaction whose sensitivity is greater than this is retained within the mechanism. In this case a threshold of $1 \times 10^{9}$ was used over all time-points. Therefore, only those reactions that are not specifically selected to remain in the mechanism at any of the time-points in any of the trajectories may be safely removed.

A further 1429 reactions were found to be redundant following application of overall sensitivity methods. Over $95 \%$ of the reactions removed at this stage were peroxy-peroxy reactions and in fact, following the application of overall sensitivities, no reactions of this type remained in the scheme, reflecting the polluted nature of the scenarios investigated, so that $\mathrm{RO}_{2}+\mathrm{NO}$ is fast. Note however, that many of the $\mathrm{RO}_{2}+\mathrm{HO}_{2}$ reactions remain. This reduced model will be referred to as Stage 2 in the following discussion.

\subsubsection{The use of a reduced set of important species}

During Stage 3 redundant species are again identified but using a smaller set of important species. When the PAN species were examined it was found that only 49 of them contributed more than $0.1 \%$ to the concentration of total PAN. 


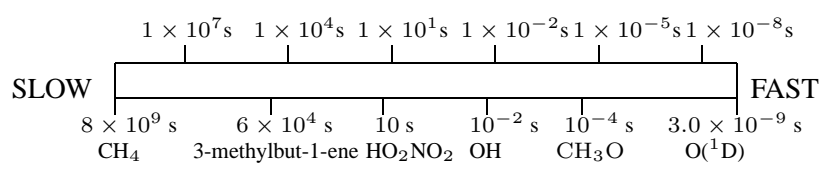

Fig. 3. Diagram showing the range of chemical lifetimes from fast to slow and examples of the lifetimes of species in the MCM.

Any species contributing less than this was no longer considered to be important. This led to a reduced set of $58 \mathrm{im}$ portant species. Again species which are necessary to this reduced set of important species are identified as described above and only 2454 species are considered to be necessary. At this stage the reaction groups relating to the formation and decomposition of minor PAN species were removed. In addition, reactions of $\mathrm{OH}$ with some minor partially oxygenated species (such as alcohols, acids, peracids and hydroperoxides) that generate acyl radical precursors were removed. Following this stage of reduction there are 2454 species and 6927 reactions remaining, showing that reactions describing the chemistry of relatively minor PAN species contribute a fairly large part of the MCM mechanism.

\subsubsection{The application of principal component analysis to the MCM}

The application of principal component analysis was then carried out for the 2454 necessary species identified in Stage 3. As the principal component analysis involves the decomposition of extremely large matrices it was not feasible to apply it to all 94 trajectories. A subset of 6 trajectories was therefore selected after examining the results from the overall sensitivity analysis. By looking at the reactions retained by each trajectory it was found that $95 \%$ of the reactions retained were selected by these 6 trajectories. It was therefore considered that sufficient coverage of conditions relevant for reduction was achieved by carrying out the principal component analysis on this subset.

Previous applications of principal component analysis to concentration sensitivity matrices as used in for example the programme package KINAL (Turányi, 1990a), have summed entries over all time-points in the trajectory. The eigenvectors and eigenvalues are then evaluated for the summation matrices. Although this approach has not been previously applied to rate sensitivity matrices, it was explored in this work due to the high cost of completing an eigenvalue eigenvector decomposition of the large matrices resulting from the high number of reactions still present in the mechanism. In order to ensure that this did not compromise the accuracy of the results, eigenvalues and eigenvectors were calculated for the rate sensitivity matrix at each chosen time-point for one trajectory. It was found that carrying out the analysis in this way for one trajectory produced approximately the same results as using the matrix summed over all chosen time-points. There- fore it was accepted that the less time consuming method was valid. Eigenvalue and eigenvector thresholds of $10^{-4}$ and 0.13 respectively were selected after experimentation with higher thresholds was shown to lead to very large errors in the reduced system. The application of principal component analysis did not lead to significant further reductions in the mechanism and only a further 8 reactions were removed. We will return to this point in the discussion. This reduced model will be referred to as Stage 4 in the following discussion.

\section{The application of time-scale based methods}

The atmospheric diffusion equation contains the physical processes, chemical transformation and deposition that together describe the time dependent behaviour of all the species in a system. Each process occurs over a particular time-scale, and within any particular model structure the physical processes are usually associated with a narrower range of time-scales than the chemical time-scales. Within a large mechanism these chemical time-scales can differ by many orders of magnitude (McRae et al., 1982). It is this very large range of time-scales that can lead to a chemical system being stiff and therefore computationally expensive to solve.

By examining the atmospheric chemical system using a dynamical systems approach, it can be shown that the longterm behaviour of the mechanism can be accurately represented by assuming that the faster time-scales equilibrate with respect to the slower ones and therefore the dimension of the system can be reduced. Various methods have exploited this time-scale separation for mechanism reduction as described in Tomlin et al. (1998). The methods include the quasi-steady-state approximation (QSSA), the slow manifold approach and the computational singular perturbation (CSP) method, each of which will be discussed briefly below. The methods are successful, since by reducing the number of fast variables within the system, both the dimension of the system (and therefore the number of equations which must be solved at each timestep) and its stiffness are reduced, thus reducing the computational burden of the model. The analysis of timescales in atmospheric systems is therefore a valuable tool for mechanism reduction.

Figure 3 shows the range of time-scales encountered in the Leeds MCM, and some of the species possessing these timescales.

Intermediate radical species, such as $\mathrm{O}$ or $\mathrm{RO}$, are highly reactive and very short lived. They quickly reach their equilibrium concentrations with respect to the slower species over time-scales of the order of $10^{-6}-10^{-9}$ s, e.g. $\mathrm{O}^{1} \mathrm{D}$ has a chemical lifetime of $3.0 \times 10^{-9} \mathrm{~s}$. NO, CO and some organic species however are associated with much slower timescales, around $10^{0}-10^{7} \mathrm{~s}$. The very fast time-scales are responsible for the equilibrium processes and are utilised in the QSSA and partial-equilibrium approximations used in 
conventional mechanism reduction. Since we are mainly interested in modelling the long-term behaviour of an atmospheric system - over a period of hours or days - it is possible to decouple the fast time-scales and assume that they reach local equilibrium with respect to the slower species. This leads to the formation of slow manifold on which the dynamics of the reduced system is contained.

\subsection{The evaluation of system timescales}

For low-dimensional systems, the investigation of timescales can be carried out through a non-dimensionalisation process often revealing small parameters within the model equations from which time-scale separation can easily be identified. For larger systems such as those typically found in tropospheric chemical mechanisms, non-dimensionalisation may be impractical, and hence perturbation methods are generally used to investigate system dynamics. The evolution of a small disturbance in a non-linear system can be used to reduce the problem to one which is locally linear. The resulting set of linear equations is easier to solve and can provide information about local time-scales and the stability of the non-linear system. Here it is applied to a more general case of systems with time-scale separation. Useful information can therefore be derived from the analysis since the concentrations of the slow species will not change significantly over the time-scale of relaxation of the perturbed species.

The rate of change of concentration in a homogeneous reaction system was described in Eq. (7). Where operator splitting is used in a reactive flow problem this formulation describes the chemical reaction step and $f(\boldsymbol{c}, \boldsymbol{k})$ can be represented as a function of the reaction rates:

$f_{i}(\boldsymbol{c}, \boldsymbol{k})=\sum_{j} v_{i j} R_{j}$

Here $i$ is the species number, $v_{i j}$ is the stoichiometric coefficient of the $i$ th species in the $j$ th reaction and $R_{j}$ is the $j$ th reaction rate.

If the system of Eq. (7) is disturbed at a particular point $c^{f_{x}}$ with a small perturbation $\Delta c_{i}$ so that

$c_{i}=c_{i}^{f i x}+\Delta c_{i}$

and this is expanded as a Taylor series, then to first order, a set of linear equations can be defined describing the motion of the perturbation,

$$
\frac{\partial \Delta c_{i}}{\partial t}=\left(\frac{\partial f_{i}}{\partial c_{1}}\right) \Delta c_{1}+\left(\frac{\partial f_{i}}{\partial c_{2}}\right) \Delta c_{2}+\ldots+\left(\frac{\partial f_{i}}{\partial c_{n}}\right) \Delta c_{n}
$$

The general solution to this equation can be written as

$$
\Delta \boldsymbol{c}(t)=e^{\int_{0}^{t} \mathbf{J}(s) d s},
$$

where $\mathbf{J}$ is the Jacobian matrix which is given by

$$
\mathbf{J}=\frac{\partial \boldsymbol{f}}{\partial \boldsymbol{c}}=\left(\begin{array}{ccc}
\frac{\partial}{\partial c_{1}}\left(\frac{\partial c_{1}}{\partial t}\right) & \ldots & \frac{\partial}{\partial c_{n}}\left(\frac{\partial c_{1}}{\partial t}\right) \\
\vdots & \vdots \\
\frac{\partial}{\partial c_{1}}\left(\frac{\partial c_{n}}{\partial t}\right) & \ldots & \frac{\partial}{\partial c_{n}}\left(\frac{\partial c_{n}}{\partial t}\right)
\end{array}\right) .
$$

If the Jacobian does not change significantly over the timescale of relaxation of the small perturbation then 16 reduces to,

$\Delta \mathbf{c}(t)=e^{\mathbf{J}(t) t} \mathbf{A}$

where $\mathbf{A}$ is a constant matrix. This is usually the case if there is sufficient time-scale separation between the fast relaxing mode and the slow mode (Tomlin et al., 2001). Equation 18 can be written in the form,

$\Delta c_{i}(t)=C_{1} e^{\lambda_{1} t}+C_{2} e^{\lambda_{2} t}+\ldots+C_{n} e^{\lambda_{n} t}$,

where $C_{i}$ depends on the size and direction of the perturbation. The exponents $\lambda_{i}$ are the eigenvalues of the Jacobian matrix calculated at the point $c^{f_{x}}$. Therefore, each time-scale of the local linear solution to the full equations has an eigenvalue associated with it. What Eq. (19) shows, is that the decay of a perturbation of an individual species may depend on several eigenvalues, and therefore time-scales, due to its coupling with other species. Perturbations which decay very rapidly are associated with large negative eigenvalues and therefore a very short time-scale. This approach is essentially local and the Jacobian will be time-dependent if there are any non-linear trajectories. Therefore the ordering of the time-scales may change as the reaction proceeds.

\subsection{The quasi-steady-state approximation (QSSA)}

\subsubsection{Definition of the QSSA}

The Quasi-Steady-State Approximation (QSSA) is perhaps the simplest method by which the system time-scales can be exploited for mechanism reduction. It equates species with time-scales, and involves the identification of species which react on very short time-scales and can therefore be assumed to be in equilibrium with respect to the slower species. For fast species such as radicals, the rate of production and consumption by chemical reaction are comparable. It can therefore be assumed that the original equation system of 7 , is reduced to a differential-algebraic system:

$$
\begin{aligned}
\frac{d c_{i}}{d t} & =f_{i}^{N} \\
0 & =f_{i}^{Q}
\end{aligned}
$$

where $N$ and $Q$ represent the non-QSSA and QSSA species respectively (Tomlin et al., 1998). The number of differential equations that must be solved in the system is reduced, and since the fast time-scales have been eliminated, the stiffness of the resulting system is also reduced. The application of 
the QSSA does not imply that the concentration of the QSSA species is constant over time but rather that $f_{i}^{Q}$ is zero when $c_{i}$ is equal to the QSSA concentration $c_{i}^{Q}$.

\subsubsection{Selection of QSSA species via the calculation of in- stantaneous errors}

Two available methods for identifying possible QSSA species based on systematic criteria are the use of singular perturbation theory developed by Lam and Goussis (1988) and the calculation of QSSA errors in Turányi et al. (1993). In this work we have utilised the latter method.

The difference in the QSSA species concentrations at an interval $\Delta t$ after the point of application of the QSSA, as calculated from Eq. (20) and (21), and Eq. (7), is the instantaneous error of the QSSA. This error represents a continuous perturbation of the calculated trajectory and causes an overall error in the concentrations of the non-QSSA species. This error feeds back to the QSSA species and so their overall error can be different from their instantaneous error. However, if the overall error of non-QSSA species is small, the overall error of QSSA species should be close to their instantaneous error (Turányi et al., 1993).

An expression for the instantaneous error $\Delta c_{i}^{s}$ on application of the QSSA to a single species has been derived in Turányi et al. (1993) as:

$\Delta c_{i}^{s}=\left|\frac{1}{J_{i i}} \frac{d c_{i}}{d t}\right|$.

If the QSSA is to be applied to several species then the error is defined as:

$\Delta c_{i}^{g}=\frac{1}{J_{i i}} \frac{d c_{i}}{d t}-\frac{1}{J_{i i}} \sum_{k \neq i} J_{i k} \Delta c_{k}^{g}$

where $\Delta c_{i}^{g}$ denotes the group error and the term that distinguishes (23) from (22) represents the interactions between the instantaneous errors of the QSSA species. If the individual and group errors remain small then the species within the chosen group can be considered as valid QSSA species (Tomlin et al., 1998).

Conducting this analysis gives an initial estimation of errors associated with the QSSA group. However, during a simulation these errors may propagate, and the careful selection of QSSA species is therefore very important. A full estimation of the validity of QSSA over a simulation can most easily be determined by comparing with the results from the simulation conducted in the absence of the QSSA approximation using the error analysis to guide the choice of QSSA group members.

The atmospheric lifetime can also be used as a criterion for the selection of the QSSA species (Hesstvedt et al., 1978). The total removal rate of a species A in the atmosphere is expressed as,

$R=[A] \sum_{i} k_{i} x_{i}$ where $[A]$ is the concentration of species $A, k_{i}$ are the rate coefficients of the second order consuming reactions of $A$, and $x_{i}$ are the concentrations of the other species involved in the reaction $i$. This equation also implicitly includes any pseudo-first-order process (eg. photolysis). The atmospheric lifetime is defined as:

$\tau_{i}=\frac{1}{\sum_{i} k_{i} x_{i}}$.

This is then related to the diagonal Jacobian element,

$\tau_{i}=-\frac{1}{J_{i i}}$,

see McRae et al. (1982). From Eq. (22) it can be seen that the instantaneous error of a single QSSA species is equal to the product of its lifetime and its net production rate. Therefore a small QSSA error requires a short lifetime and/or slow rates of change for a species. A slow rate of change is therefore not essential for the application of QSSA as the error will be negligible if the lifetime of the species is small compared to the net production of the species.

\subsection{Application of the QSSA to the MCM}

Following the application of sensitivity analysis to the MCM, the reduced mechanism consists of 2454 species and 6919 reactions. Individual QSSA errors were calculated using Eq. (22). Any species having an absolute QSSA error of less than $3 \times 10^{-2}$ at each time point in every trajectory was considered to be a QSSA species. The tolerance level for inclusion of species into the QSSA species group was selected by examination of the range of values and then locating a gap in the sequence of values. In total, 557 QSSA species were identified.

Those species with only one consuming reaction were removed and reactions combined in the following manner. If

$$
\begin{aligned}
\mathrm{D}+\mathrm{E} & \longrightarrow \mathrm{A}+\mathrm{PROD}_{2} \text { rate coefficient }=k_{1} \\
\mathrm{~A} & \longrightarrow \mathrm{C}+\mathrm{PROD}_{1} \text { rate coefficient }=k_{2}
\end{aligned}
$$

where A is the QSSA species, then A can be replaced in Eq. (27) by:

$\mathrm{D}+\mathrm{E} \longrightarrow \mathrm{C}+\mathrm{PROD}_{1}+\mathrm{PROD}_{2}$ rate coefficient $=k_{1}$.

343 species could be removed from the MCM in this way. Almost all of these species were alkoxy radicals with only one consuming reaction at the previous stage that was either decomposition or reaction with oxygen.

79 of the QSSA species had more than one parallel consuming reaction although the rates for these were not temperature and therefore time dependent. These reactions were removed as follows. If A is defined as a QSSA species and

$$
\mathrm{A} \longrightarrow \mathrm{B}+\mathrm{PROD}_{1} \text { rate coefficient }=k_{1}
$$


Table 3. Rate coefficients for example removing $\left[\dot{\mathrm{OOC}}\left(\mathrm{CH}_{3}\right) \mathrm{CHO}\right]^{*}$.

\begin{tabular}{ll}
\hline equation number & rate coefficient $\left(\right.$ molecule $\left.\mathrm{cm}^{-3}\right) \mathrm{s}^{-1}$ \\
\hline$(34)-(36)$ & $1.00 \times 10^{-18}$ \\
$(37)$ & $1.20 \times 10^{-17}$ \\
$(38)$ & $0.89 \mathrm{KDEC}$ \\
$(39)$ & $0.11 \mathrm{KDEC}$ \\
\hline
\end{tabular}

$$
\mathrm{A} \longrightarrow \mathrm{E}+\mathrm{PROD}_{2} \text { rate coefficient }=k_{2}
$$

$\mathrm{C}+\mathrm{D} \longrightarrow \mathrm{A}+\mathrm{PROD}_{3}$ rate coefficient $=k_{3}$

then $\mathrm{A}$ is replaced in Reaction 32 by

$$
\frac{k_{1}}{k_{1}+k_{2}}\left(\mathrm{~B}+\mathrm{PROD}_{1}\right)+\frac{k_{2}}{k_{1}+k_{2}}\left(\mathrm{E}+\mathrm{PROD}_{2}\right) \text {. }
$$

The majority of these species were excited Criegee biradicals, of which $\left[\dot{\mathrm{OOOC}}\left(\mathrm{CH}_{3}\right) \mathrm{CHO}\right]^{*}$ is an example. It is formed from unsaturated dicarbonyls and the oxidation of alkylbenzenes and isoprene. The biradical is formed in the reactions,

$$
\begin{gathered}
\mathrm{CHOC}\left(\mathrm{CH}_{3}\right)=\mathrm{CHC}(\mathrm{O}) \mathrm{C}_{2} \mathrm{H}_{5}+\mathrm{O}_{3} \longrightarrow \\
\mathrm{CHOC}(\mathrm{O}) \mathrm{C}_{2} \mathrm{H}_{5}+\left[\dot{\mathrm{OOC}}\left(\mathrm{CH}_{3}\right) \mathrm{CHO}\right]^{*} \\
\mathrm{CHOC}\left(\mathrm{CH}_{3}\right)=\mathrm{CHC}(\mathrm{O}) \mathrm{C} \mathrm{H}_{3}+\mathrm{O}_{3} \longrightarrow \\
\mathrm{CHOC}(\mathrm{O}) \mathrm{CH}_{3}+\left[\mathrm{O} O \dot{\mathrm{C}}\left(\mathrm{CH}_{3}\right) \mathrm{CHO}\right]^{*} \\
\mathrm{CHOCH}=\mathrm{C}\left(\mathrm{OH}_{3}\right) \mathrm{CHO}+\mathrm{O}_{3} \longrightarrow \\
\mathrm{CHO}_{2}+\left[\dot{\mathrm{O} O C}\left(\mathrm{CH}_{3}\right) \mathrm{CHO}\right]^{*} \\
\mathrm{CHOC}\left(\mathrm{CH}_{3}\right)=\mathrm{CHC}_{2} \mathrm{H}_{4} \mathrm{OH}+\mathrm{O}_{3} \longrightarrow \\
\mathrm{HOCH}_{2} \mathrm{CHO}+\left[\dot{\mathrm{O} O \dot{C}}\left(\mathrm{CH}_{3}\right) \mathrm{CHO}\right]^{*},
\end{gathered}
$$

and reacts via,

$$
\begin{aligned}
& {\left[\dot{\mathrm{OOOC}}\left(\mathrm{CH}_{3}\right) \mathrm{CHO}\right]^{*} \longrightarrow \mathrm{OH}+\mathrm{CO}+\mathrm{CH}_{3} \mathrm{O}_{3}} \\
& {\left[\dot{\mathrm{OOOC}}\left(\mathrm{CH}_{3}\right) \mathrm{CHO}\right]^{*} \longrightarrow \dot{\mathrm{OOC}}\left(\mathrm{CH}_{3}\right) \mathrm{CHO}}
\end{aligned}
$$

where the rate coefficients of the equations are given in Table 3 and KDEC is defined as $10^{6} \mathrm{~s}^{-1}$ (Pilling et al., 1999).

From Eq. (38) and (39) [ÖOC் $\left.\left(\mathrm{CH}_{3}\right) \mathrm{CHO}\right]^{*}$ can be expressed as

$$
\begin{aligned}
{\left[\dot{\mathrm{OOC}}\left(\mathrm{CH}_{3}\right) \mathrm{CHO}\right]^{*}=} & 0.89\left(\mathrm{OH}+\mathrm{CO}+\mathrm{CH}_{3} \mathrm{CO}_{3}\right) \\
& +0.11\left(\dot{\mathrm{OOC}}\left(\mathrm{CH}_{3}\right) \mathrm{CHO}\right) .
\end{aligned}
$$

i.e. there is competition between decomposition to form $\mathrm{OH}$ and formation of the excited criegee biradical which primarily reacts with $\mathrm{CO}$ to form methylglyoxyl. The $\mathrm{OH}$ channel represents a significant radical formation route.

Substituting this into Eq. (34) to (37) and removing Eq. (38) and (39) the set of equations is reduced to,

$$
\mathrm{CHOC}\left(\mathrm{CH}_{3}\right)=\mathrm{CHC}(\mathrm{O}) \mathrm{C}_{2} \mathrm{H}_{5}+\mathrm{O}_{3} \longrightarrow
$$

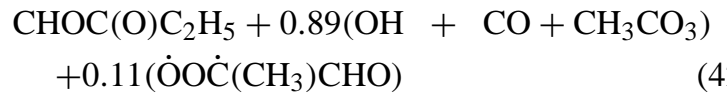

$\mathrm{CHOC}\left(\mathrm{CH}_{3}\right)=\mathrm{CHC}(\mathrm{O}) \mathrm{C}_{2} \mathrm{H}_{5}+\mathrm{O}_{3} \longrightarrow$

$\mathrm{CHOC}(\mathrm{O}) \mathrm{C}_{2} \mathrm{H}_{5}+0.89\left(\mathrm{OH}+\mathrm{CO}+\mathrm{CH}_{3} \mathrm{CO}_{3}\right)$

$+0.11\left(\dot{\mathrm{OOO}} \dot{\mathrm{C}}\left(\mathrm{CH}_{3}\right) \mathrm{CHO}\right)$

$$
\begin{gathered}
\mathrm{CHOC}\left(\mathrm{CH}_{3}\right)=\mathrm{CHC}(\mathrm{O}) \mathrm{CH}_{3}+\mathrm{O}_{3} \longrightarrow \\
\mathrm{CHOC}(\mathrm{O}) \mathrm{CH}_{3}+0.89\left(\mathrm{OH}+\mathrm{CO}+\mathrm{CH}_{3} \mathrm{CO}_{3}\right) \\
+0.11\left(\dot{\mathrm{O}} \dot{\mathrm{C}}\left(\mathrm{CH}_{3}\right) \mathrm{CHO}\right) \\
\mathrm{CHOCH}=\mathrm{C}\left(\mathrm{OH}_{3}\right) \mathrm{CHO}+\mathrm{O}_{3} \longrightarrow \\
\mathrm{CHO}_{2}+0.89\left(\mathrm{OH}+\mathrm{CO}+\mathrm{CH}_{3} \mathrm{CO}_{3}\right) \\
+0.11\left(\dot{\mathrm{O}} \dot{\mathrm{C}}\left(\mathrm{CH}_{3}\right) \mathrm{CHO}\right) \\
\mathrm{CHOC}\left(\mathrm{CH}_{3}\right)=\mathrm{CHC}_{2} \mathrm{H}_{4} \mathrm{OH}+\mathrm{O}_{3} \longrightarrow \\
\mathrm{HOCH}_{2} \mathrm{CHO}+0.89\left(\mathrm{OH}+\mathrm{CO}+\mathrm{CH}_{3} \mathrm{CO}_{3}\right) \\
+0.11\left(\dot{\mathrm{O}} \dot{\mathrm{C}}\left(\mathrm{CH}_{3}\right) \mathrm{CHO}\right),
\end{gathered}
$$

where the rate coefficients remain as before.

A further 55 species can be removed in a similar manner to this, but as their rate coefficients are time-dependent the coefficient ratios within the lumped equations must be recalculated at each iteration, for example $\mathrm{O}^{1} \mathrm{D}$.

$$
\begin{aligned}
\mathrm{O}_{3} \longrightarrow \mathrm{O}^{1} \mathrm{D} k_{1} & =J(1) \\
\mathrm{O}^{1} \mathrm{D} \longrightarrow 2 \mathrm{OH} k_{2} & =2.20 \times 10^{-10} \mathrm{H}_{2} \mathrm{O} \\
\mathrm{O}^{1} \mathrm{D} \longrightarrow \mathrm{O} \quad k_{3} & =3.20 \times 10^{-11} \mathrm{O}_{2} e^{\frac{70}{T E M P}}
\end{aligned}
$$

The expression for $\mathrm{O}^{1} \mathrm{D}$ can be expressed as

$$
\frac{k_{2}}{k_{2}+k_{3}}(2 \mathrm{OH})+\frac{k_{3}}{k_{2}+k_{3}}(\mathrm{O}) \text {. }
$$

It can be seen that both $k_{2}$ and $k_{3}$ are time-dependent and therefore the ratios in the expression for $\mathrm{O}^{1} \mathrm{D}$ must be recalculated after each iteration. Equation (47) will then become,

$\mathrm{O}_{3} \longrightarrow \frac{k_{2}}{k_{2}+k_{3}}(2 \mathrm{OH})+\frac{k_{3}}{k_{2}+k_{3}}(\mathrm{O})$.

The 55 QSSA species in this group were mainly alkoxy radicals undergoing both decomposition and reaction with oxygen in the previous reduced scheme.

Sixty-six QSSA species remain which cannot be removed by any of the above methods. These could potentially be removed by creating explicit expressions for the removed species by setting their rate equations equal to zero. This was only implemented for one species, $\mathrm{O}$, and resulted in an algebraic expression for $\mathrm{O}$ of the following form:

$$
[O]=\frac{k_{3}\left[\mathrm{NO}_{3}\right]+k_{4}\left[\mathrm{NO}_{2}\right]+k_{5}\left[\mathrm{O}_{2}\right]+k_{6} \frac{k_{2}}{k_{1}+k_{2}}\left[\mathrm{O}_{2}\right]}{k_{7}\left[\mathrm{NO}_{2}\right]+k_{8}\left[\mathrm{NO}_{2}\right]+k_{9}[\mathrm{NO}]+k_{10}\left[O_{3}\right]+k_{11}},
$$

where the rate expressions are given in Table 4. KMT01 and KMT02 both represent fall-off reactions of the following 
Table 4. Rate coefficients used in algebraic expression for $\mathrm{O}$ (Pilling et al., 1999; Atkinson et al., 1992) where M is a third body usually represented by $\left[\mathrm{N}_{2}\right]$.

\begin{tabular}{ll}
\hline rate coefficient $\left(\text { molecules } \mathrm{cm}^{-3}\right)^{m-1} \mathrm{~s}^{-1}$ \\
$k_{3}=\quad 1.85 \times 10^{-1}(\cos \theta)^{0.189} e^{-0.112 \sec \theta}$ \\
$k_{4}=\quad 1.11 \times 10^{-2}(\cos \theta)^{0.397} e^{-0.183 \sec \theta}$ \\
$k_{5}=\quad 5.22 \times 10^{-4}(\cos \theta)^{0.322} e^{-0.079 \sec \theta}$ \\
$k_{6}=\quad 8.98 \times 10^{-5}(\cos \theta)^{1.436} e^{-0.936 \sec \theta}$ \\
$k_{7}=\quad \mathrm{KMT} 02$ \\
& $k_{0}=9.0 \times 10^{-32}\left(\frac{T E M P}{300}\right)^{-2.0} \mathrm{M}$ \\
& $k_{\infty}=2.2 \times 10^{-11}$ \\
& $F_{c}=e^{\frac{-T E M P}{1300}}$ \\
$k_{8}=$ & $6.50 \times 10^{-12} e^{\frac{120}{T E M P}}$ \\
$k_{9}=$ & $\mathrm{KMT} 01$ \\
& $k_{0}=1.0 \times 10^{-31}\left(\frac{T E M P}{300}\right)^{-1.6} \mathrm{M}$ \\
& $k_{\infty}=3.0 \times 10^{-11}\left(\frac{T E M P}{300}\right)^{0.3}$ \\
& $F_{c}=e^{\frac{-T E M P}{1850}}$ \\
& $8.00 \times 10^{-12} e^{\frac{2060}{T E M P}}$ \\
$k_{10}=$ & $6.00 \times 10^{-34} \mathrm{O}_{2} \mathrm{M}\left(\frac{T E M P}{300}\right)^{-2.3}$ \\
$k_{11}=$ &
\end{tabular}

form: $k=\left(\frac{k_{0} k_{\infty}}{k_{0}+k_{\infty}}\right) F$, where $\log F=\frac{\log F_{c}}{1+\left(\log \left(k_{0} / k_{\infty}\right)\right)^{2}}$ (Atkinson et al., 1992).

This expression can be substituted for $[\mathrm{O}]$ in all equations, and therefore leads to the removal of one species. Unfortunately this method leads to highly complicated, and often nonlinear, algebraic expressions when used for other remaining QSSA species that may require solution using iterative methods. For this reason the method has only been applied to a single species at this stage, in order to avoid excessively complicating the mechanism before further lumping stages. An additional drawback for these highly coupled QSSA species is that their removal can only be achieved using complex algebraic expressions within the model code. The explicit description of the chemical model in kinetic form is lost at this stage of reduction as a result. The final reduced mechanism after the application of the QSSA will be addressed as Stage 5 in the following discussion.

\section{The existence of slow manifolds within the model}

\subsection{Intrinsic Low Dimensional Manifold (ILDM) methods}

The concept of the low-dimensional or slow manifold was first introduced to atmospheric systems by Lorenz (1986). It is particularly useful in homogeneous chemical systems or systems employing operator splitting, since the slow manifold describes the long-term behaviour of the chemical sys- tem once the fast modes have died away. The QSSA represents a subset of such slow manifold based techniques since it assumes that fast species locally equilibrate. However, as demonstrated above, the QSSA assumes that time-scales are associated with individual or groups of QSSA species. In highly coupled systems this may not always be the case as complex functions of species may in fact create fast and slow time-scales. The concept of the ILDM therefore utilises a geometric approach to time-scale separation, which may in some cases lead to higher levels of reduction in the number of system variables than the QSSA.

Geometrically, the dynamics of the system in species phase space can be seen as reaction trajectories relaxing onto a series of increasingly lower-dimensional manifolds, which was interpreted in Roussel and Fraser (1991) as a "cascade through a nested hierarchy of smooth interfaces (inertial manifolds)". Scenarios with quite different initial conditions approach these attracting manifolds, and the slow time-scales govern the long term dynamics. The aim of mechanism reduction is to find the lowest dimension manifold - the intrinsic manifold - which will still represent the important longterm features of the reaction (Lowe and Tomlin, 2000), and to develop a model that provides a time-dependant representation of the slow dynamics. Several methods have been developed which allow the description of the system dynamics relating to the remaining intermediate modes. These include the use of look-up tables describing the slow dynamics, the QSSA, where algebraic functions for the non-intermediate modes are used, and repromodelling methods, where fitted models such as polynomial difference equations are formulated for the intermediate dynamics (Lowe and Tomlin, 2000).

\subsection{Time-scale modes and species couplings}

If the full chemical mechanism contains $n_{s}$ species, then $n_{s}$ coupled ODEs define the system, which therefore has $n_{s}$ different time-scales associated with it. If the system is assumed to be in equilibrium with respect to its $n_{f}$ fastest time-scales, these can be decoupled from the system. In addition, a number of species or combinations of species may remain approximately constant over time. These form $n_{c}$ conservation relations, of which element conservation in the mechanism is an example. The behaviour of the system can then be described independently from the conservation relations and the decoupled fast time-scales and hence by a smaller number of variables $n_{g}$, where $n_{g}=n_{s}-n_{f}-n_{c}$. Estimating the intrinsic dimension of the system is useful since it provides guidelines for the application of ILDM type methods. It also allows us to assess whether the QSSA has successfully removed all possible fast time-scales from the model.

In order to determine the intrinsic system dimension $n_{g}$, the system is first transformed into a new set of variables called time-scale modes which are each related to a single time-scale of the system. If $\lambda_{1}, \ldots, \lambda_{n}$ are distinct eigenval- 
ues of $\mathbf{J}$ and $\mathbf{X}_{r}$ and $\mathbf{X}_{l}$ the matrices of its corresponding right and left eigenvectors then we define a new set of variables $\boldsymbol{z}$ where

$z=\mathbf{X}_{l}^{T} \boldsymbol{c}$

and

$\frac{d z}{d t}=\mathbf{X}_{l}^{T} \boldsymbol{f}$

Conversely it follows that the inverse transformation matrix $\mathbf{X}_{r}$ exists and transforms the new variables back to the original species concentrations:

$\boldsymbol{c}=\mathbf{X}_{r} z$.

Using perturbation analysis (Tomlin et al., 2001) showed that the time-dependance of a perturbation in $\mathbf{z}$ is given by:

$\Delta \boldsymbol{z}(t)=e^{\operatorname{diag}\left(\lambda_{1}, \ldots, \lambda_{n}\right) t} \Delta \boldsymbol{z}_{\mathbf{0}}$.

The system will therefore respond to a perturbation in $z$ according to single time-scales, each perturbation growing or decaying exponentially depending on the size and sign of the eigenvalues. The variables $z$ can therefore be considered as the modes of the system. Physically what this means is that the lumping matrix $\mathbf{X}_{\mathbf{I}}^{\mathbf{T}}$ shows us how each species contributes to the modes associated with each eigenvalue or system time-scale. By ordering the eigenvalues we can see which species are associated with the fast and slow modes of the system. This result is similar to CSP analysis and can allow us to identify species contributing to the fast decaying modes which can potentially be removed.

Assuming we can order the eigenvalues according to their values from large and negative to large and positive we can separate the system into fast, intermediate and slow modes. This can either be achieved by identifying large gaps in the spectrum of eigenvalues or by comparison of chemical timescales with typical transport processes. We therefore partition the lumping matrix $\mathbf{X}_{l}^{T}$ into slow, intermediate and fast parts:

$\mathbf{X}_{l}^{T}=\left[\begin{array}{c}\mathbf{X}_{l f}^{T} \\ \mathbf{X}_{l i}^{T} \\ \mathbf{X}_{l s}^{T}\end{array}\right]$,

allowing the modes to be separated into fast:

$z_{f}=\mathbf{X}_{l f}^{T} \boldsymbol{c}$

intermediate

$z_{i}=\mathbf{X}_{l i}^{T} \boldsymbol{c}$

and slow modes:

$\boldsymbol{z}_{s}=\mathbf{X}_{l s}^{T} \boldsymbol{c}$.

In a similar way to the application of the QSSA, a model describing the long term dynamics of the system need only describe the intermediate modes since the fast ones can be assumed to be in local equilibrium and the slow ones assumed to represent some kind of conservation equation.
6.3 Estimating the underlying dimensionality of the trajectories

By ordering the eigenvalues as above we can consider individual modes $i$ and investigate their collapse onto what is essentially an (n-1) dimensional manifold. It has been shown previously in Tomlin et al. (2001) that the equation describing the decay of each fast mode is given by:

$\frac{d z_{i}}{d t}=\mathbf{X}_{l, \lambda_{i}}^{T} \frac{d \mathbf{c}}{d t}=\mathbf{X}_{l, \lambda_{i}}^{T} \boldsymbol{f}$,

where $\mathbf{X}_{l, \lambda_{i}}^{T}$ is the transpose of the left eigenvector associated with eigenvalue $\lambda_{i}$. If the mode has collapsed then $\mathbf{X}_{l, \lambda_{i}}^{T} f=0$ giving the equivalent of the Maas and Pope (1992) equation defining an (n-1) dimensional manifold following from the collapse of an individual mode $z_{i}$. Where the trajectory is close to the manifold (i.e. in the region of the fixed point about which the original expansion was made) we can estimate the normalised distance of an individual mode i from an (n-1) dimensional manifold using the equation:

$\Delta \tilde{z}=\frac{\mathbf{X}_{l, \lambda_{i}}^{T} f}{\lambda_{i}} \frac{1}{\left(\kappa+\left|\mathbf{X}_{l, \lambda_{i}}^{T} \boldsymbol{c}\right|\right)}$,

where $\kappa$ is a small parameter included to avoid division by zero.

Following the ideas of Roussel and Fraser (1991) we can imagine the system collapsing onto a cascade of manifolds of decreasing dimension with the fastest modes collapsing first and the slowest last. By estimating the distance of each mode from each (n-1) dimensional manifold and comparing against a tolerance parameter we can therefore determine at each time-point along the trajectory how many modes have effectively collapsed. It also follows that once the fastest mode has collapsed then the error of assuming an (n-2) dimensional manifold can be estimated by the distance of the next slowest mode from the manifold. If we assume $\mathrm{n}_{f}$ fast modes therefore, the error associated with the $\left(\mathrm{n}-\mathrm{n}_{f}\right)$ dimensional slow manifold will be largely determined by the distance of the $z_{n_{f}}$ mode from the manifold although there may be some contribution from the faster modes.

The number of linear conservation relations which hold for the system can be determined by finding those modes whose eigenvalues are equal or close to zero. A very small eigenvalue signifies slow rate of change and therefore signifies variables or combinations of variables which remain approximately constant over time. This does not imply that the concentration of specific species must remain constant over time but that certain species maintain a fixed relationship with other species throughout the calculation. This means that groups of species maybe conserved. Again, a user tolerance $c t o l$ is defined and a conservation relation is defined for $|\operatorname{Re}(\lambda(i))| \leq c t o l$. The definition of manifold dimension is therefore given by

dimension $=n_{s}-n_{c}-n_{f}$. 
Table 5. Number of lifetimes in time-scale ranges for each reduced mechanism for trajectory 7 after 36 hours.

\begin{tabular}{lllll}
\hline range of life-times $\frac{1}{|\lambda|}(\mathrm{s})$ & \multicolumn{4}{l}{ number remaining } \\
& full & Stage 1 & Stage 3 & Stage 5 \\
\hline fast $<1 \times 10^{-4}$ & 711 & 710 & 434 & 6 \\
intermediate & 2359 & 2175 & 1915 & 1863 \\
slow $>1 \times 10^{5}(\approx 1$ day $)$ & 416 & 205 & 105 & 100 \\
\hline total & 3487 & 3091 & 2454 & 1969 \\
\hline
\end{tabular}

The dimension therefore depends on selected user tolerances, the choice of which will affect the final accuracy of the model. In general there are usually gaps in the spectrum of eigenvalues and therefore ctol might be chosen by first looking at how the spectrum changes over time and choosing an appropriate gap.

\subsection{Linking slow manifold distance to QSSA error}

Equation (62) gives an estimation for $\Delta \tilde{\mathbf{z}}$. If the system is completely uncoupled, the eigenvalues will be equal to the Jacobian diagonals and the set of eigenvectors will be equivalent to the identity matrix. So substituting,

$\lambda_{i}=J_{i i}=-\frac{1}{\tau_{i}}$ and $X_{l, \lambda_{i}}^{T}=I$

where $\tau_{i}$ is the chemical lifetime of species $i$, gives,

$$
\left|\Delta z_{i}\right|=\left|f_{i} \tau_{i}\right|=\left|\Delta c_{i}^{q s s a}\right|
$$

This effectively demonstrates the equivalence of QSSA errors and the distance from the slow manifold for this special situation where no coupling exists between the fast variables.

\subsection{Evaluation of Time-scales Remaining Following the Application of the QSSA}

Examination of the range of time-scales remaining in a mechanism is a good way of identifying the sorts of methods that would lead to effective further reduction. For example, very little will be gained by applying ILDM methods to a system with very few fast time-scales remaining. The number of slow, fast and intermediate time-scales remaining at each stage of the reduction is presented for trajectory 7 after $36 \mathrm{~h}$ in Table 5. The table shows that following the application of the QSSA at Stage 5 of the reduction, most of the fast time-scales have been removed from the mechanism. This demonstrates that in this case the QSSA species as a group relate to the fast modes of the system and that the QSSA ia an effective method for removing the fast timescales. The large number of intermediate time-scales in the stage 3 mechanism implies that the application of ILDM type methodologies for the reduction of fast time-scales would be
Table 6. Reactions and species remaining at each stage.

\begin{tabular}{lllll}
\hline $\begin{array}{l}\text { stage of } \\
\text { reduction }\end{array}$ & $\begin{array}{l}\text { number of } \\
\text { reactions } \\
\text { remaining }\end{array}$ & $\begin{array}{l}\text { \% reactions } \\
\text { remaining }\end{array}$ & $\begin{array}{l}\text { number of } \\
\text { species } \\
\text { remaining }\end{array}$ & $\begin{array}{l}\% \text { species } \\
\text { remaining }\end{array}$ \\
\hline full & 10763 & 100 & 3487 & 100 \\
stage 1 & 9839 & 91.4 & 3091 & 88.6 \\
stage 2 & 8410 & 78.1 & 3091 & 88.6 \\
stage 3 & 6927 & 64.4 & 2454 & 70.3 \\
stage 4 & 6919 & 64.2 & 2454 & 70.3 \\
stage 5 & 6168 & 57.3 & 1969 & 56.4 \\
\hline
\end{tabular}

extremely difficult. The commonly used methods for representing the dynamics on the slow manifold such as the use of look-up tables or fitted polynomial difference equations would become prohibitively expensive for a system of such high underlying dimensionality. In the case of an explicit mechanism like the MCM the use of the relatively simple QSSA method has therefore proven to be much more effective, although ILDM methods have previously been successfully applied to highly lumped atmospheric chemical mechanisms (Lowe and Tomlin, 2000). Since very few fast modes remain following the application of the QSSA, other methods will have to be sought in order to achieve further reduction as discussed in Whitehouse et al. (2004).

\section{Comparison between full and reduced schemes}

\subsection{Comparison for original box model conditions}

The number of species and reactions remaining at each stage of the reduction are presented in Table 6 . The dimension of the system has been reduced by a factor of 2 at Stage 5 of the reduction with an associated decrease in simulation time of a factor of 4.

Comparisons between the full and reduced mechanisms for selected trajectories and important species can be seen in Figs. 4 to 12. The differences between the diurnal profiles of $\mathrm{NO}_{2}$ for scenarios 7 and 25 reflect the large differences in emission rates for the two scenarios. Scenario 25 represents much lower $\mathrm{VOC}$ and $\mathrm{NO}_{\mathrm{x}}$ emissions than scenario 7. In scenario 25 the $\mathrm{NO}_{2}$ concentration is therefore always low $(0-8 \mathrm{ppb})$ and shows a minimum in the late afternoon reflecting the maximum removal rate by photolysis and by nitrate formation. The maximum concentrations occur in the early morning reflecting reduced photochemical activity. The maximum $\mathrm{NO}_{2}$ concentrations are much higher for the high VOC emission scenario shown in Fig. 4 and these considerations result in only small variations in the overall rate of increase of the $\mathrm{NO}_{2}$ concentration. The daily maxima in $[\mathrm{OH}]$ concentration decrease on the second and third days of each scenario, reflecting increased scavenging of $\mathrm{OH}$ by VOCs as their concentrations build. Rate of production 
analysis (ROPA) for $\mathrm{OH}$ demonstrates that the rates of the reaction of $\mathrm{OH}$ with oxgenates increase over the 3 days of the simulation, highlighting the importance of such intermediates later in the scenarios. The chosen scenarios therefore reflect a range of concentrations of both primary pollutants and important intermediates providing a stringent test of the reduced mechanisms. The figures show that the errors resulting from the reduction procedures are fairly small over a wide range of concentration conditions. Although a small accumulation in errors occurs on the third day of simulation, these are still within an acceptable level.

7.2 Comparison of reduced mechanisms using a European trajectory model

Although generated under polluted urban conditions it is desirable that the reduced mechanisms are accurate over as wide a range of conditions as possible. In order to test this wider applicability, the production of eight species is presented over the course of a European scale trajectory using the 1D Harwell Trajectory model (Derwent et al., 1996). This trajectory follows an episode that developed over Europe, ending in Birmingham in order to coincide with the PUMA campaign measurements, and provides an opportunity to investigate how well the reduced mechanisms stand up outside of the conditions for which they were specifically developed.

The Harwell Trajectory model (Derwent and Nodop, 1986) is used to describe the chemical development of a parcel of boundary layer air. The emission terms are time and species dependent and depend on the location of the air parcel within the emissions grid. The emission terms are obtained by dividing the pollutant emission rate in mass per unit area per unit time by the boundary layer depth. The emission rates are taken from the following inventories,

- The EMEP emissions inventory is disaggregated over $150 \times 150 \mathrm{~km}$ grid squares and represents the total biogenic emissions expressed in 100 tonnes per year as isoprene.

- The OECD-CORINAIR inventory expresses data in tonnes per year per $50 \times 50 \mathrm{~km}$ grid-square with the VOCs split into non-methane hydrocarbons (NMVOCs) and methane. All data are summed over all categories and area and point sources.

- The UK NAEI uses $10 \times 10 \mathrm{~km}$ disaggregated grid squares to represent emissions of $\mathrm{CO}, \mathrm{NO}_{\mathrm{x}}, \mathrm{SO}_{2}$ and NMVOCs over the UK.

The emissions are then assigned to individual species within the MCM according to the NAEI as described above. The deposition velocities used in the Lagrangian trajectory model are a function of the species concentration, and the time dependant boundary layer depth as described in Derwent et al. (1996). The deposition rate is therefore a function of the local species concentration depending on the position of the air parcel.

In the Lagrangian simulation the initial concentrations of peroxy radicals, total peroxy acyl nitrates and non methane VOC compounds were assumed to be zero. Non zero initial concentrations were assigned to the following species: $\mathrm{NO}=0.2 \mathrm{ppb}, \mathrm{NO}_{2}=0.78 \mathrm{ppb}, \mathrm{CO}=120 \mathrm{ppb}, \mathrm{HCHO}=2 \mathrm{ppb}$, $\mathrm{CH}_{4}=1.8 \mathrm{ppm}, \mathrm{O}_{3}=50 \mathrm{ppb}, \mathrm{H}_{2}=500 \mathrm{ppb} . \mathrm{O}_{2}$ and $\mathrm{N}_{2}$ assumed typical atmospheric concentrations throughout the simulation. The local concentrations throughout the scenario are also highly dependant on the path of the trajectory and therefore the emissions into the moving air parcel. Figure 10 indicates that high emissions of $\mathrm{NO}_{\mathrm{x}}$ and VOCs are encountered on the second and third days of the scenario as demonstrated by the sharp increase in $\mathrm{NO}, \mathrm{NO}_{2}$ and $\mathrm{HCHO}$ concentrations. The simulation therefore covers fairly unpolluted conditions at the start of the trajectory, followed by the injection of high emissions of $\mathrm{NO}_{\mathrm{x}}$ and VOCs on days 2 and 3 and subsequently the ageing of the air mass towards the end of the simulation as increased levels of $\mathrm{O}_{3}$ and peroxy acyl nitrates are formed. Comparison of the full and reduced mechanisms for this scenario therefore made it possible to examine the the accuracy of the reduced schemes during the chemical development of air parcels travelling over Europe.

This investigation was carried out using the full mechanism and reduced mechanisms at Stages 2, 3 and 5. It was necessary to restore the reaction

$$
\mathrm{CH}_{4}+\mathrm{OH} \longrightarrow \mathrm{CH}_{3} \mathrm{O}_{2}
$$

rate coefficient $=7.44 \times 10^{-18} \mathrm{TEMP}^{2} \exp (-1361 / \mathrm{TEMP})$

to the reduced scheme, since it is important to include the oxidation of $\mathrm{CH}_{4}$ for non-polluted conditions such as those found at the start of the trajectory. Although it reacts slowly with $\mathrm{OH}$ compared to other VOCs, when its background atmospheric concentration is high, it makes a major contribution to $\mathrm{OH}$ loss when the concentration of other VOCs is low.

The comparisons between full and reduced mechanisms are plotted in Figs. 13 and 14. In Fig. 13 the photochemical generation of ozone along the idealised trajectory shows a small deviation compared to the full mechanism. The greatest disparities occur at around 90 and $120 \mathrm{~h}$, where the concentration of ozone is under predicted by $5 \%$ to $13 \%$. The comparison of NO also exhibits a small deviation from the full mechanism, although less than that for ozone. On examination of the remaining figures a similar situation can be seen for each species. The largest jump in error occurs between Stage 2 and Stage 3, with an extremely small increase in error between Stage 3 and Stage 5 where the QSSA was applied. The worst results were found in the simulations of total PAN. The simulated concentrations rise steadily over the five-day trajectory exhibiting a clear diurnal afternoon peak. This rise coincides with increasing emissions of VOC into the atmosphere, and is perhaps not surprising since some of the minor PAN species were excluded from the list of important species at this stage. 

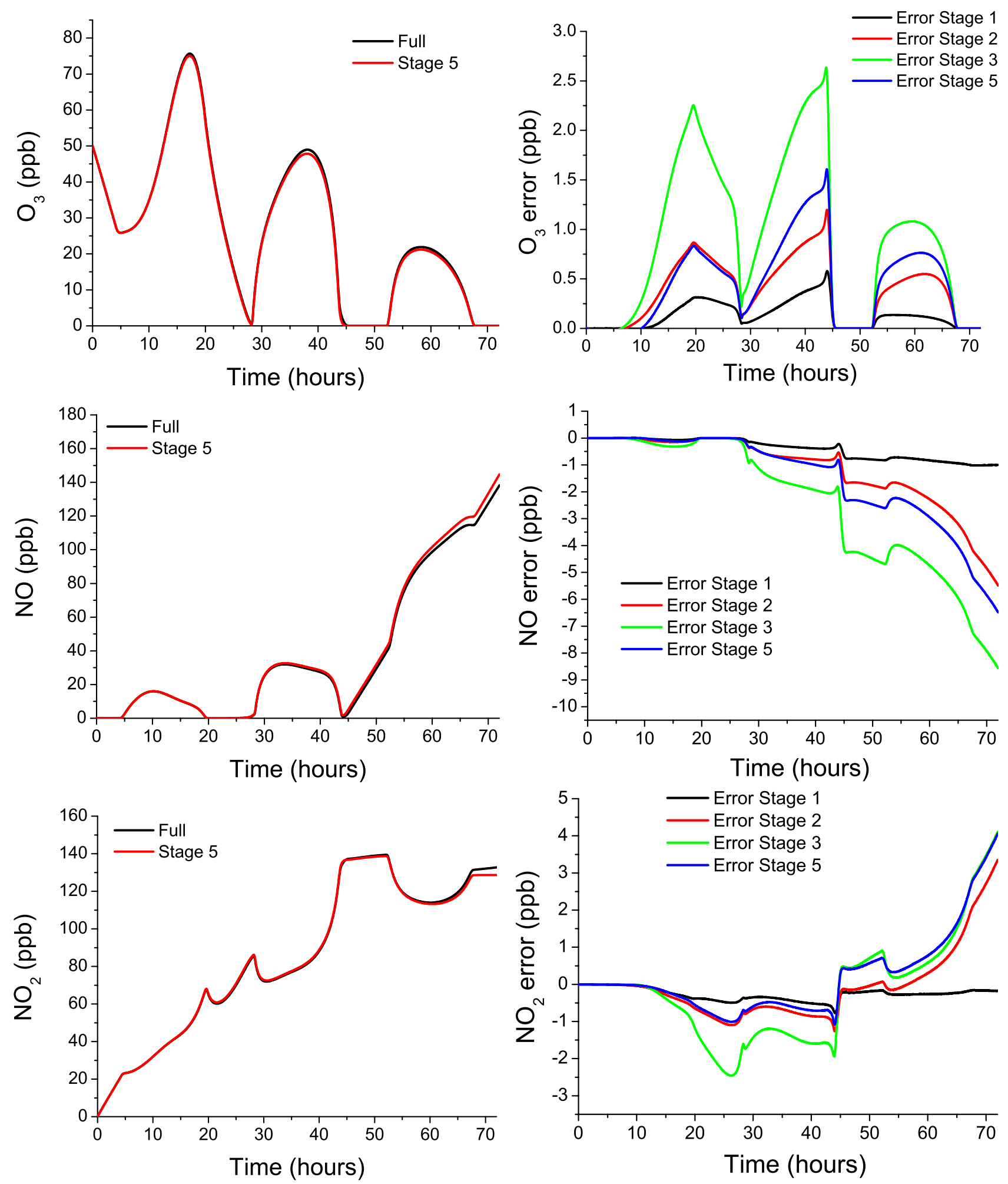

Fig. 4. Comparison of full and Stage 5 schemes for trajectory 7 along with errors for each stage for $\mathrm{O}_{3}, \mathrm{NO}$ and $\mathrm{NO}_{2}$. 

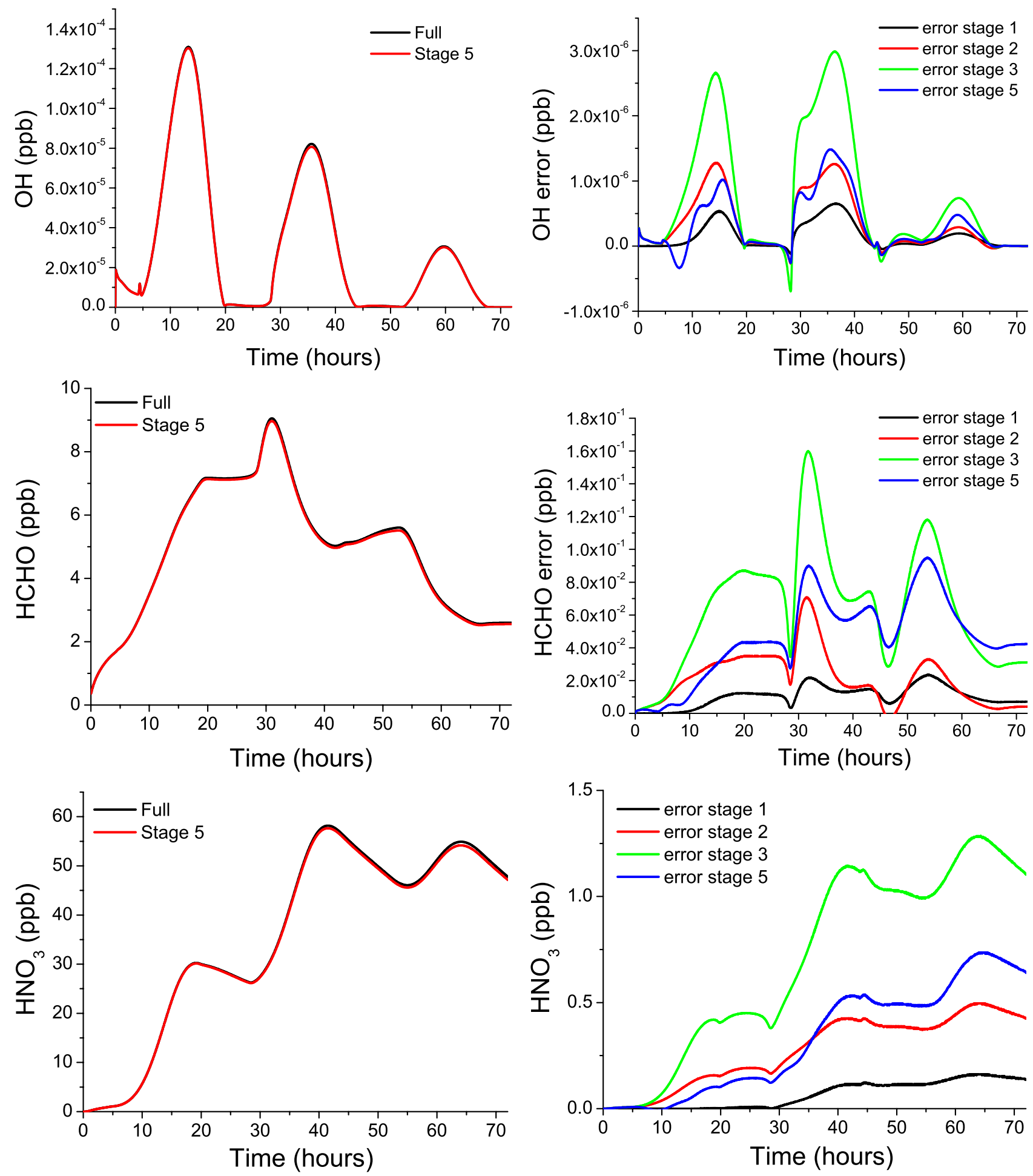

Fig. 5. Comparison of full and Stage 5 schemes for trajectory 7 along with errors for each stage for $\mathrm{OH}, \mathrm{HCHO}$ and $\mathrm{HNO}_{3}$. 

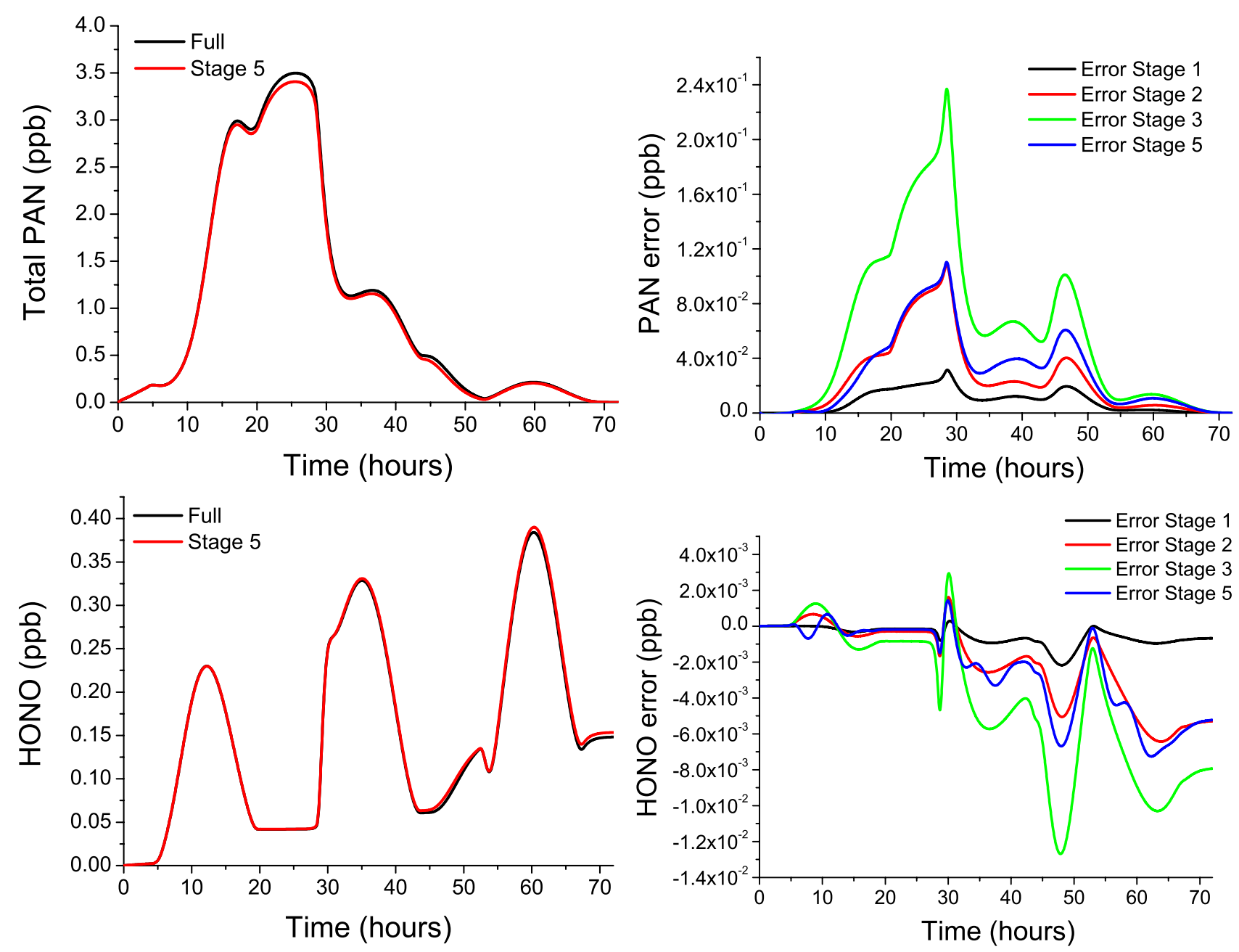

Fig. 6. Comparison of full and Stage 5 schemes for trajectory 7 along with errors for each stage for PAN and HONO. 

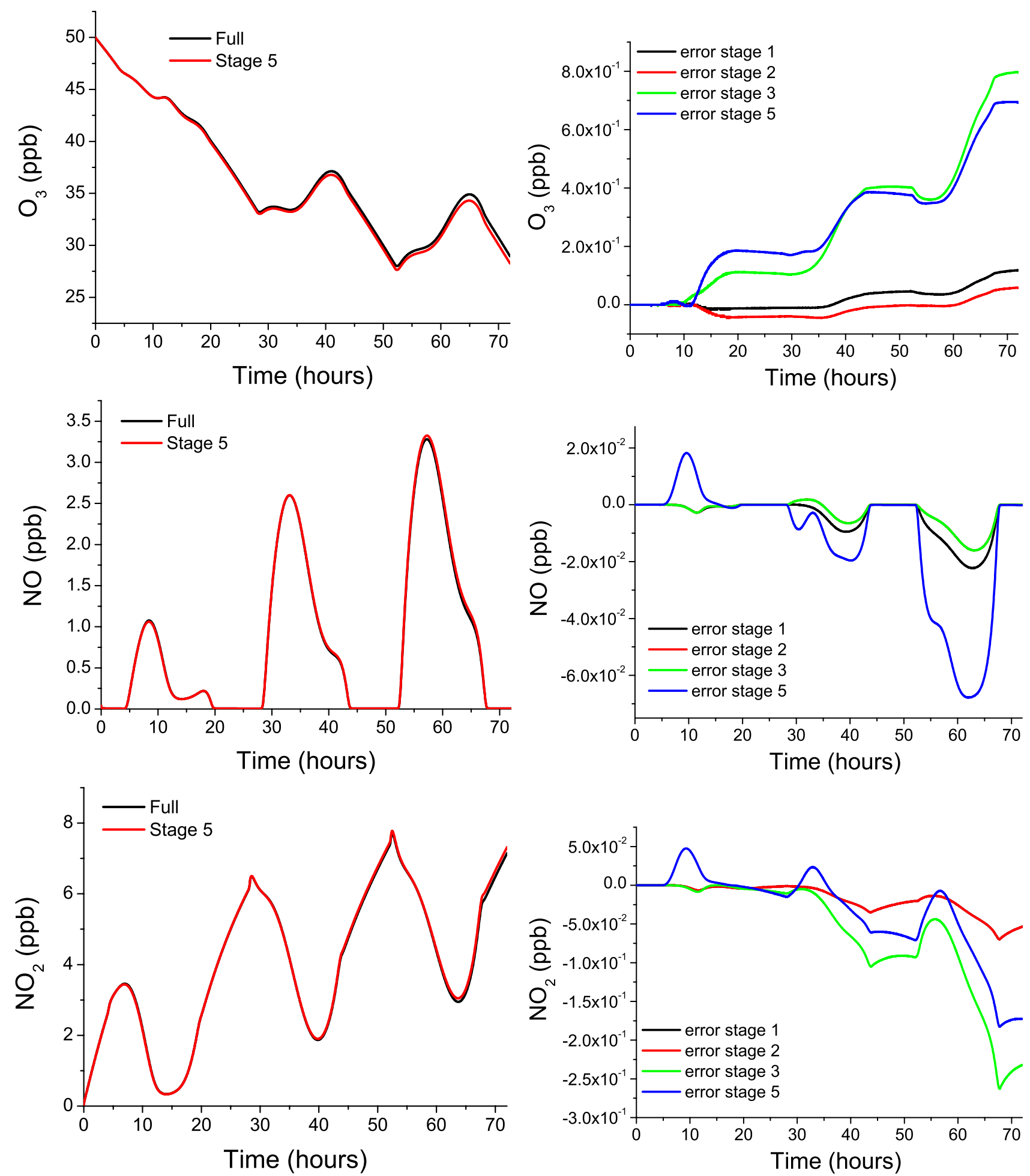

Fig. 7. Comparison of full and Stage 5 schemes for trajectory 25 along with errors for each stage for $\mathrm{O}_{3}, \mathrm{NO}_{\text {and }} \mathrm{NO}_{2}$. 

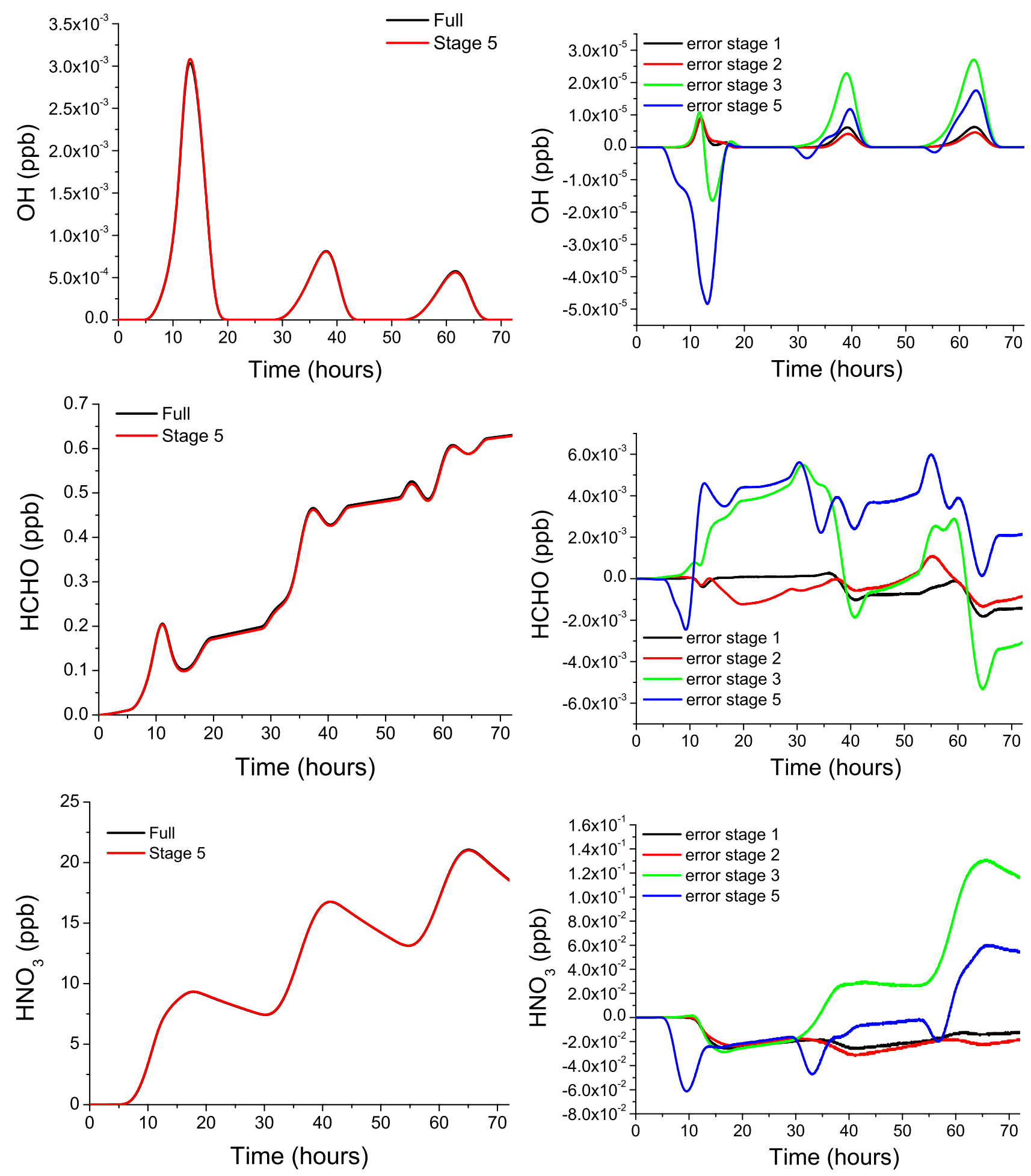

Fig. 8. Comparison of full and Stage 5 schemes for trajectory 25 along with errors for each stage for $\mathrm{OH}, \mathrm{HCHO}$ and $\mathrm{HNO}_{3}$. 

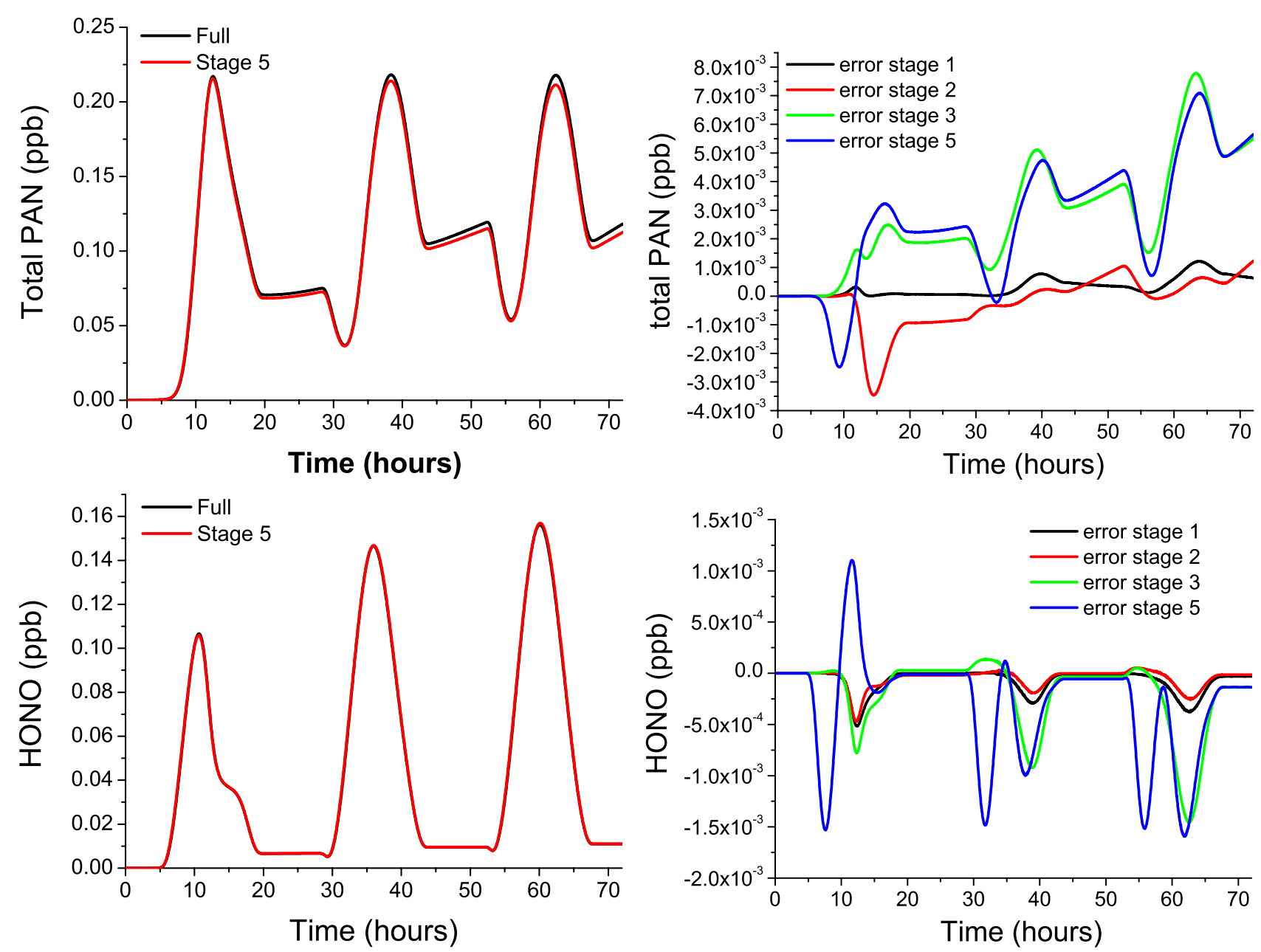

Fig. 9. Comparison of full and Stage 5 schemes for trajectory 25 along with errors for each stage for PAN and HONO. 

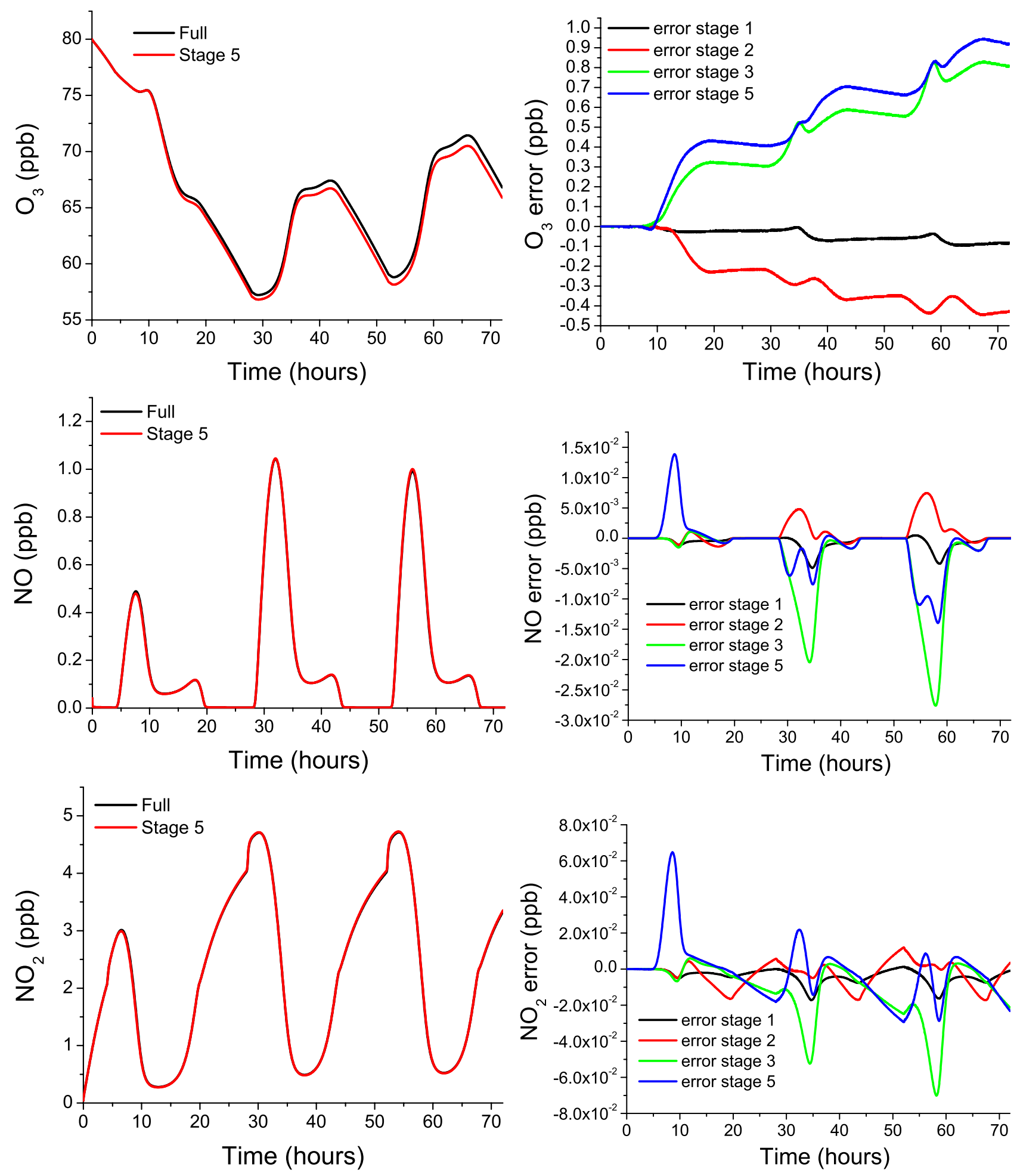

Fig. 10. Comparison of full and Stage 5 schemes for trajectory 63 along with errors for each stage for $\mathrm{O}_{3}, \mathrm{NO}$ and $\mathrm{NO}_{2}$. 

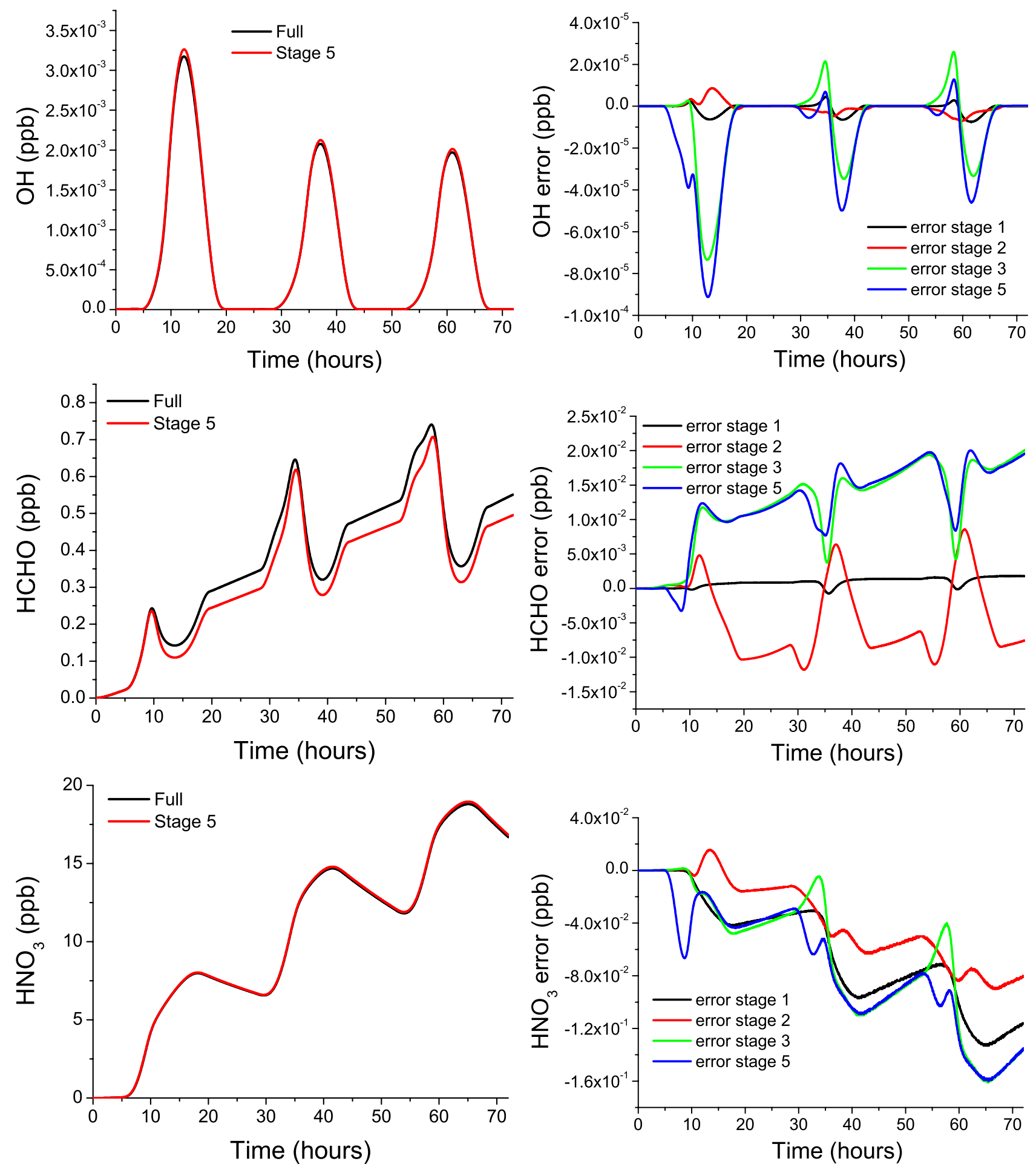

Fig. 11. Comparison of full and Stage 5 schemes for trajectory 63 along with errors for each stage for $\mathrm{OH}, \mathrm{HCHO}$ and $\mathrm{HNO}_{3}$. 

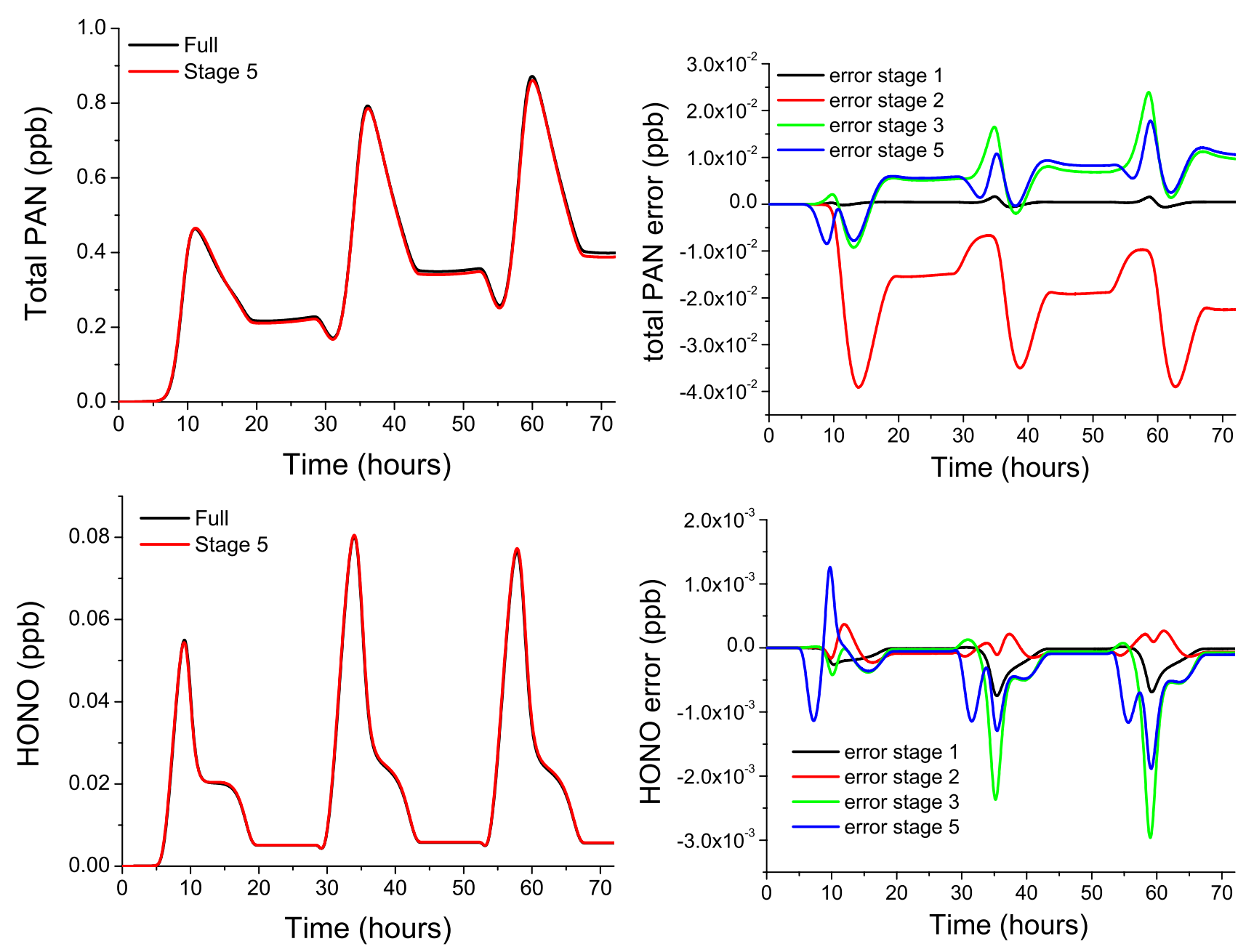

Fig. 12. Comparison of full and Stage 5 schemes for trajectory 63 along with errors for each stage for PAN and HONO. 

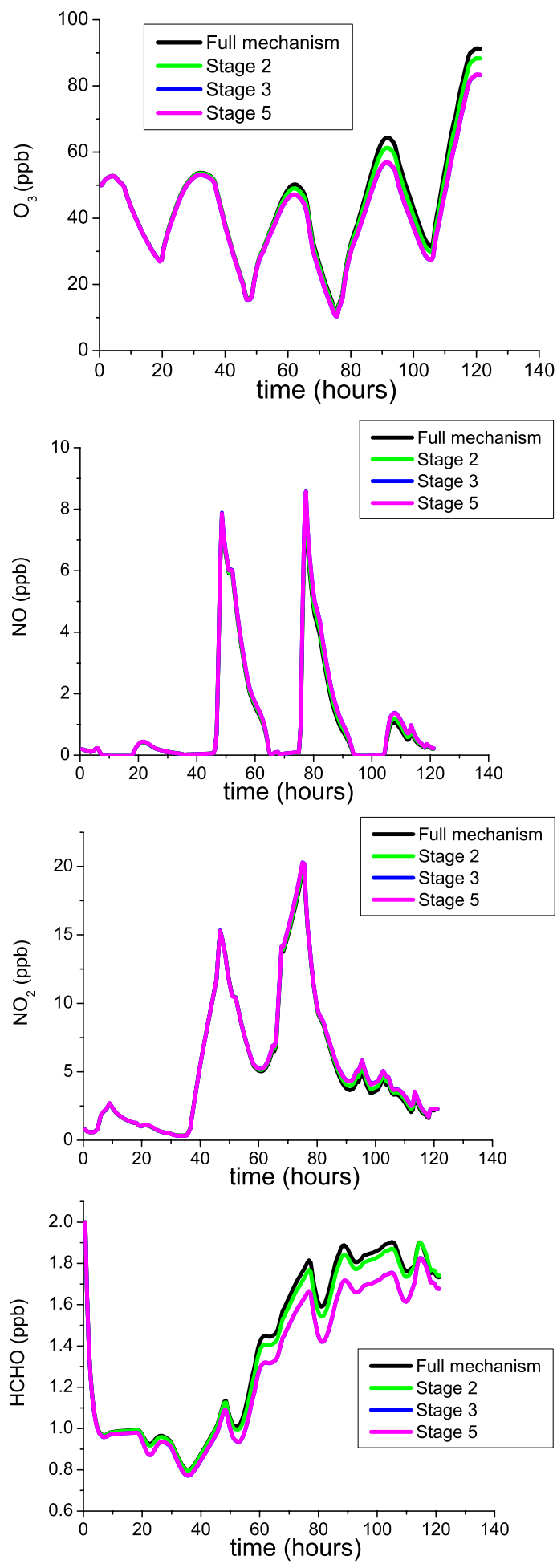

Fig. 13. Plots for PUMA trajectory run for $\mathrm{O}_{3}, \mathrm{NO}, \mathrm{NO}_{2}, \mathrm{HCHO}$.

The accuracy levels found here are slightly worse than the trends found using the scenarios over which the reduced mechanisms were developed, although still within acceptable limits. When conducting a mechanism reduction of this na-
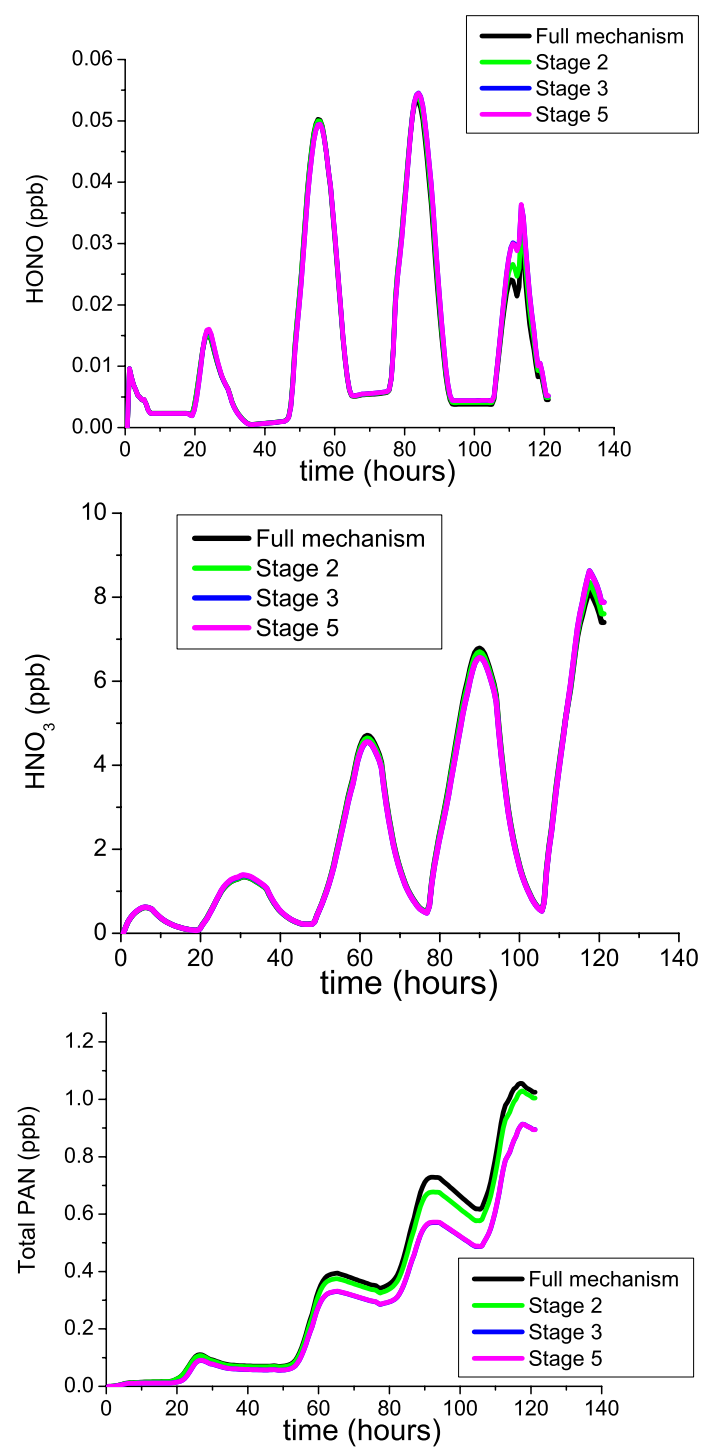

Fig. 14. Plots for PUMA trajectory run for $\mathrm{HONO}, \mathrm{HNO}_{3}$, total PAN.

ture the only conditions over which the mechanism can be assumed to be accurate are those for which the analysis on which the reductions were carried out was based. If the examination of trajectories over conditions outside those previously considered produced results as good as, or better than those obtained from the defined data set then this is a very positive piece of evidence. The more conditions over which these mechanisms can be demonstrated to be accurate the more basis there is for assuming that they can be used to model $\mathrm{O}_{3}, \mathrm{NO}_{\mathrm{x}}$, PAN and VOCs within the troposphere under other un-tested conditions within the range considered to be typical for polluted environments. 


\section{Discussion}

The first stages of the approach taken towards mechanism reduction in this work were derived from the protocol described in Heard et al. (1998) and Zeng et al. (1997). First, those species in which we are primarily interested were determined from the full MCMv2.0. which contains 10763 reactions and 3487 species (Pilling et al., 1999). Simulations were performed using the full mechanism for 94 box model simulations where initial concentrations and emissions were chosen to cover a wide range of urban conditions. Next, redundant species were identified and removed from the mechanism. At Stage 1, 396 species and 1224 reactions were removed from the mechanism leaving 9839 reactions.

Then, redundant reactions were removed by calculating the local rate sensitivity matrix and using overall sensitivity measures and principal component analysis as a way of interpreting the resulting matrix. Adaptations had to be made in order to cover the inherent problems of carrying out mechanism reduction on a system as large as the MCM. System sparsity was exploited where possible and methods were automated to a high degree. Using overall sensitivities the mechanism was reduced to 8410 reactions. All peroxyperoxy radical reactions were removed during this stage, indicating that this loss mechanism for peroxy radicals is of much lower importance under urban and moderately polluted conditions than the reaction with inorganic nitrogen containing species.

Before principal component analysis was carried out further species were removed using a second stage of identification of redundant species using a smaller set of important species. At this stage some minor PAN species were removed from the important species list leaving a set of 58 important species. This step was added as the large number of species still remaining in the system meant that the eigenvector eigenvalue analysis of the Jacobian, necessary to carry out principal component analysis, was too computationally expensive to be carried out for all the trajectories. Only 2454 species were considered to be necessary to model this reduced set of important species, involving 6927 reactions. The greatest deterioration in accuracy has occurred after this second removal of redundant species. This suggests that the PAN species removed as insignificant may have been influential when treated as a whole group. A potentially better method of reducing the number of PAN species would have been to define a species TOTALPAN where

$[$ TOTALPAN $]=\sum_{i}\left[\right.$ PAN $\left._{i}\right]$

where $\mathrm{PAN}_{i}$ represents the 184 PAN species. Then a single rate equation

$\frac{d f \text { [TOTALPAN }]}{d k_{i}}$

could have been examined. In this way those PAN species important to the production of TOTALPAN could have been identified and retained by the user, instead of defining them a priori. However, the errors still remained small for Stage 3 over quite a wide range of conditions.

In the fourth stage of reduction, principal component analysis on the sensitivity matrix was carried out. 2454 eigenvalues were retained as there were still 2454 necessary species present, signifying the maximum number of potentially relevant eigenvalues. An eigenvector tolerance of 0.13 was used. The large reduction at the previous stage did however mean that very little further reduction could be achieved using principal component analysis without seriously compromising the accuracy of the mechanism. Despite extensive experimentation with potential thresholds, it was found that those which allowed accuracy to be maintained permitted the removal of only a further 8 reactions. This was potentially due to the fact that the MCM consists of many parallel reaction chains (Jenkin et al., 1997) which have very little cross coupling between them. This led to many reactions being removed using overall concentration sensitivity analysis leaving very few reactions remaining that were suitable for removal using principal component analysis. This is an important result for the future application of sensitivity analysis for the reduction of highly detailed tropospheric mechanisms, since avoiding the use of the computationally expensive principal component analysis could speed up the reduction process considerably.

The final stages of mechanism reduction involved identifying QSSA species and removing them by lumping reactions, and defining algebraic expressions for the QSSA species as functions of the non-QSSA species. The selection of QSSA species was found to lend itself very well to automation using local QSSA errors. Once a threshold had been selected a list of QSSA species was easily assembled from the data produced by each simulation. The species which were identified as being suitable for removal as QSSA species consist mainly of two species types. Most, were alkoxyradicals which decompose very quickly to produce an aldehyde and water. The remaining species were predominantly excited Criegee biradicals. One of the other species which has been identified as a QSSA species is $\mathrm{O}^{1} \mathrm{D}$, an excited oxygen atom, which having been formed by the photolysis of ozone, reacts very quickly with $\mathrm{N}_{2}, \mathrm{H}_{2} \mathrm{O}$ or $\mathrm{O}_{2}$ to form $\mathrm{OH}$ or a ground state oxygen atom $\mathrm{O}^{3} \mathrm{P}$. Again, due to the very short life-time of this species, it was an obvious QSSA species as the intermediate steps which pass through $\mathrm{O}^{1} \mathrm{D}$ can easily be lumped without impinging on the accuracy of the mechanism. Since this species is associated with extremely fast time-scales, its removal reduces the stiffness of the rate equation system considerably.

The application of the QSSA to the MCM is designed to remove fast time-scales from the mechanism, and the suitability of this technique for application to the MCM was investigated. It was shown that the number of fast time-scales has decreased from 478 before the removal of QSSA species to 6 after their removal. A small number of intermediate and 
slow time-scales were also removed. The decrease from $20 \%$ to $0.2 \%$ of the time-scales in the system being considered fast, shows a high level of success for removal species via the QSSA and a resulting decrease in dimension of the system. The application of the QSSA by simple reaction lumping for a very large number of species allows the basic structure of the chemical mechanism to be maintained giving significant advantages over other more geometric based techniques such as the ILDM for future kinetic studies. In this case, the large number of intermediate time-scales within the mechanism make the application of ILDM type methods impossible.

The removal of species from the mechanism leads to a decrease in the amount of computational time required to solve the system. This occurs by approximately a factor of $n^{2}$. In the Stage 5 reduced mechanism there are 1969 species, a decrease of a factor of approximately 2 . In practice, the solver shows a speed up of approximately 4 making this assumption reasonably accurate. This factor of $n^{2}$ speed up could be considered to be due to the extensive use of $n \times n$ matrices in implicit integration routines.

The reduced mechanisms were shown to vary slightly in accuracy across the range of trajectories over which they were reduced. Most trajectories are well represented and the errors are less than 5\% at all times. The reduced mechanism was also shown to be applicable over a long range trajectory calculation with the addition of only the reaction methane $+\mathrm{OH}$ that is relevant for unpolluted conditions. Some divergence was noted at the end of the 5 day trajectory but in general the performance of the reduced schemes was within acceptable limits, demonstrating potentially wide applicability.

\subsection{Further reduction of the mechanism}

At Stage 5 the mechanism contains 1969 species and 6168 reactions. Whilst the mechanism has been shown to be applicable over a wide range of conditions and can be computed 4 times faster than the full mechanism, it is still desirable to reduce it further. Conducting time-scale analysis on the system shows that there are large numbers of intermediate time-scales still present in the reduced mechanism. The application of ILDM methods has been discounted and therefore other methods should be sought. An approach commonly used is species lumping, where a group of species can be represented in the mechanism by a single variable. In this way a smaller set of equations are needed to represent the dynamics of the chemical system and the number of intermediate time-scales would be reduced. The further application of lumping to the MCMv2.0. is described in the following companion paper.

\section{Conclusions}

Several methods for mechanism reduction have been introduced and shown to be applicable using automated methods to complex tropospheric mechanisms such as the Master Chemical Mechanism. In particular, the methods of local concentration sensitivity analysis and overall rate sensitivity analysis proved to be efficient and capable of removing the majority of redundant reactions in the scheme across a wide range of conditions. The application of principal component analysis of the rate sensitivity matrix proved to be computationally very expensive due to its use of the decomposition of very large matrices. For a mechanism such as the MCM, where a large number of parallel reaction chains exist, its use did not prove to be effective in finding additional redundant reactions over and above the use of overall sensitivities.

The use of the QSSA also proved to be an extremely successful method of removing the fast time-scales within the system. The calculation of instantaneous QSSA errors was capable of automatically choosing potential groups of QSSA species based on user selected tolerances. Due to the fact that many of the QSSA species could be easily removed by reaction lumping, its application allowed a kinetic structure to be retained within the mechanism in contrast to other timescale based methods such as the ILDM. Although they have proved successful within highly lumped schemes such as in Lowe and Tomlin (2000), due to the high number of intermediate time-scale remaining in MCM mechanism, the use of methods such as the ILDM would not be possible without significant further reduction using other methods.

Analysis of the errors obtained by using the most reduced mechanism were determined to be less than $5 \%$ for many of the trajectories studied, and less than $10 \%$ for the majority. Those trajectories which showed disappointing levels of accuracy were in the very high $\mathrm{NO}_{\mathrm{x}}$ and high VOC ranges of the conditions studied and would be considered to be at the extremes of conditions found in even polluted UK cities. Furthermore, it was found that with the addition of a reaction relevant to non-polluted environments, the reduced mechanism was capable of accurately predicting a trajectory describing the formation of a range of secondary species across Europe. The success of the mechanism under conditions well outside of those under which it was generated suggests that the reduced schemes are of quite wide applicability.

Finally, the use of the reduction techniques discussed here has allowed the development of a set of staged mechanisms with varying dimensions and accuracies to allow a user to choose the most appropriate level according to the desired application. An investigation was also carried out into the automation of reduction techniques such as the identification of redundant species, overall sensitivity analysis, principal component analysis, QSSA analysis and reaction lumping. This means that reduced mechanisms can be generated in a systematic way without the need for extensive manual analysis of data. 


\section{Appendix 1}

Table 7. Initial $\mathrm{O}_{3}$ concentrations, desired maximum VOC concentrations and $\mathrm{VOC}$ to $\mathrm{NO}_{\mathrm{x}}$ ratios for each trajectory scenario and the emissions rates used to achieve them.

\begin{tabular}{|c|c|c|c|c|c|c|}
\hline \multicolumn{3}{|c|}{ initial $\mathrm{O}_{3}(\mathrm{ppb})$} & \multicolumn{2}{|c|}{ Desired conditions } & \multirow{3}{*}{$\begin{array}{l}\text { VOC emission rates } \\
\left(\text { molecules } \mathrm{cm}^{-3} \mathrm{~s}^{-1} \text { ) }\right.\end{array}$} & \multirow{3}{*}{$\begin{array}{l}\mathrm{NO}_{\mathrm{x}} \text { emission rates } \\
\left(\text { molecules } \mathrm{cm}^{-3} \mathrm{~s}^{-1}\right)\end{array}$} \\
\hline 50 & 80 & 20 & $\max \mathrm{VOC}$ & $\frac{V O C}{N O X}$ & & \\
\hline \multicolumn{3}{|c|}{ trajectory number } & & & & \\
\hline & 33 & 66 & 700 & 1.2 & $1.80 \times 10^{8}$ & $7.00 \times 10^{7}$ \\
\hline 1 & 34 & 67 & 500 & 1.2 & $1.50 \times 10^{8}$ & $5.50 \times 10^{7}$ \\
\hline 2 & 35 & 68 & 300 & 1.2 & $9.50 \times 10^{7}$ & $4.80 \times 10^{7}$ \\
\hline 3 & 36 & 69 & 250 & 1.2 & $9.00 \times 10^{7}$ & $4.50 \times 10^{7}$ \\
\hline 4 & 37 & 70 & 200 & 1 & $4.30 \times 10^{7}$ & $1.00 \times 10^{7}$ \\
\hline 5 & 38 & 71 & 200 & 1.2 & $8.50 \times 10^{7}$ & $4.00 \times 10^{7}$ \\
\hline 6 & 39 & 72 & 150 & 0.78 & $4.50 \times 10^{7}$ & $1.00 \times 10^{7}$ \\
\hline 7 & 40 & 73 & 150 & 1 & $3.80 \times 10^{7}$ & $6.00 \times 10^{5}$ \\
\hline 8 & 41 & & 150 & 1.45 & $8.30 \times 10^{7}$ & $3.80 \times 10^{7}$ \\
\hline 9 & 42 & 74 & 100 & 0.45 & $4.00 \times 10^{7}$ & $7.80 \times 10^{6}$ \\
\hline 10 & 43 & 75 & 100 & 0.8 & $4.00 \times 10^{7}$ & $6.50 \times 10^{6}$ \\
\hline 11 & 44 & & 100 & 1.1 & $2.55 \times 10^{7}$ & $1.35 \times 10^{7}$ \\
\hline 12 & 45 & & 100 & 1.8 & $2.65 \times 10^{7}$ & $1.55 \times 10^{7}$ \\
\hline 13 & 46 & 76 & 75 & 0.34 & $9.00 \times 10^{6}$ & $1.12 \times 10^{6}$ \\
\hline 14 & 47 & & 75 & 1 & $2.25 \times 10^{7}$ & $1.15 \times 10^{7}$ \\
\hline 15 & 48 & 77 & 75 & 1.5 & $5.00 \times 10^{7}$ & $1.00 \times 10^{7}$ \\
\hline 16 & 49 & 78 & 75 & 2.1 & $5.05 \times 10^{7}$ & $8.80 \times 10^{6}$ \\
\hline 17 & 50 & 79 & 50 & 0.25 & $8.50 \times 10^{6}$ & $1.12 \times 10^{6}$ \\
\hline 18 & 51 & 80 & 50 & 1 & $2.00 \times 10^{7}$ & $8.98 \times 10^{6}$ \\
\hline 19 & 52 & 81 & 50 & 1.75 & $5.00 \times 10^{7}$ & $8.50 \times 10^{6}$ \\
\hline 20 & 53 & 82 & 50 & 2.6 & $3.50 \times 10^{7}$ & $7.00 \times 10^{6}$ \\
\hline 21 & 54 & 83 & 20 & 0.25 & $8.50 \times 10^{6}$ & $1.12 \times 10^{6}$ \\
\hline 22 & 55 & 84 & 20 & 1 & $9.00 \times 10^{6}$ & $2.24 \times 10^{6}$ \\
\hline 23 & 56 & 85 & 20 & 2 & $2.05 \times 10^{7}$ & $9.50 \times 10^{6}$ \\
\hline 24 & 57 & 86 & 20 & 4.2 & $2.60 \times 10^{7}$ & $1.50 \times 10^{7}$ \\
\hline 25 & 58 & 87 & 10 & 0.35 & $4.60 \times 10^{6}$ & $6.55 \times 10^{5}$ \\
\hline 26 & 59 & 88 & 10 & 1 & $7.00 \times 10^{6}$ & $2.24 \times 10^{6}$ \\
\hline 27 & 60 & 89 & 10 & 3 & $1.05 \times 10^{7}$ & $6.73 \times 10^{6}$ \\
\hline 28 & 61 & 90 & 10 & 6 & $1.10 \times 10^{7}$ & $1.12 \times 10^{7}$ \\
\hline 29 & 62 & 91 & 5 & 0.4 & $4.10 \times 10^{6}$ & $1.12 \times 10^{6}$ \\
\hline 30 & 63 & 92 & 5 & 1 & $2.45 \times 10^{6}$ & $9.35 \times 10^{5}$ \\
\hline 31 & 64 & 93 & 5 & 3 & $2.45 \times 10^{6}$ & $2.81 \times 10^{6}$ \\
\hline 32 & 65 & 94 & 5 & 8 & $4.61 \times 10^{6}$ & $5.61 \times 10^{6}$ \\
\hline
\end{tabular}


Table 8. Relative emissions factors for individual VOCs as calculated from Eq. (5) in Sect. 3.2.

\begin{tabular}{|c|c|c|}
\hline MCM name & species name & emissions ratio \\
\hline $\mathrm{HCHO}$ & METHANAL (FORMALDEHYDE) & $7.20 \times 10^{-3}$ \\
\hline $\mathrm{C} 2 \mathrm{H} 6$ & ETHANE & $6.52 \times 10^{-3}$ \\
\hline $\mathrm{CH} 3 \mathrm{OH}$ & METHANOL & $1.40 \times 10^{-3}$ \\
\hline $\mathrm{C} 2 \mathrm{H} 5 \mathrm{OH}$ & ETHANOL & $3.69 \times 10^{-3}$ \\
\hline $\mathrm{CH} 3 \mathrm{CHO}$ & ETHANAL (ACETALDEHYDE) & $1.21 \times 10^{-3}$ \\
\hline NPROPOL & 1-PROPANOL (N-PROPANOL) & $5.47 \times 10^{-2}$ \\
\hline $\mathrm{C} 3 \mathrm{H} 8$ & PROPANE & $1.91 \times 10^{-2}$ \\
\hline IPROPOL & 2-PROPANOL (I-PROPANOL) & $9.47 \times 10^{-3}$ \\
\hline $\mathrm{C} 2 \mathrm{H} 5 \mathrm{CHO}$ & PROPANAL (PROPRIONALDEHYDE) & $1.38 \times 10^{-3}$ \\
\hline NBUTOL & 1-BUTANOL (N-BUTANOL) & $1.02 \times 10^{-2}$ \\
\hline $\mathrm{CH} 3 \mathrm{COCH} 3$ & PROPANONE (ACETONE) & $1.22 \times 10^{-2}$ \\
\hline BUT2OL & 2-BUTANOL (SEC-BUTANOL) & $8.50 \times 10^{-3}$ \\
\hline $\mathrm{NC} 4 \mathrm{H} 10$ & N-BUTANE & $6.21 \times 10^{-2}$ \\
\hline IBUTOL & 2-METHYL-1-PROPANOL (I-BUTANOL) & $2.48 \times 10^{-3}$ \\
\hline $\mathrm{C} 3 \mathrm{H} 7 \mathrm{CHO}$ & BUTANAL (BUTYRALDEHYDE) & $7.24 \times 10^{-4}$ \\
\hline NC5H12 & PENTANE (N-PENTANE) & $3.72 \times 10^{-2}$ \\
\hline MEK & BUTANONE (METHYL ETHYL KETONE) & $1.25 \times 10^{-2}$ \\
\hline $\mathrm{C} 3 \mathrm{H} 6$ & PROPENE (PROPYLENE) & $1.44 \times 10^{-2}$ \\
\hline IC4H10 & 2-METHYL-PROPANE (I-BUTANE) & $2.19 \times 10^{-2}$ \\
\hline IPEBOH & 3-METHYL-2-BUTANOL & $6.46 \times 10^{-5}$ \\
\hline IPRCHO & METHYLPROPANAL (I-BUTYRALDEHYDE) & $5.95 \times 10^{-5}$ \\
\hline BUT1ENE & 1-BUTENE & $4.32 \times 10^{-3}$ \\
\hline TBUTOL & 2-METHYL-2-PROPANOL (T-BUTANOL) & $3.12 \times 10^{-4}$ \\
\hline MGLYOX & METYHL GLYOXAL & $9.52 \times 10^{-6}$ \\
\hline $\mathrm{C} 4 \mathrm{H} 9 \mathrm{CHO}$ & PENTANAL (VALERALDEHYDE) & $6.25 \times 10^{-5}$ \\
\hline MIBK & $\begin{array}{l}\text { 4-METHYL 2-PENTANONE } \\
\text { (METHYL I-BUTYL KETONE) }\end{array}$ & $8.56 \times 10^{-3}$ \\
\hline IC5H12 & 2-METHYLBUTANE (1-PENTANE) & $3.25 \times 10^{-2}$ \\
\hline $\mathrm{M} 22 \mathrm{C} 4$ & 2,2-DIMETHYLBUTANE & $1.86 \times 10^{-3}$ \\
\hline MIPK & 3-METHYL 2-BUTANONE & $3.76 \times 10^{-7}$ \\
\hline $\mathrm{NC} 7 \mathrm{H} 16$ & $\begin{array}{l}\text { HEPTANE (N-HEPTANE) } \\
\text { (METHYL I-PROPYL KETONE) }\end{array}$ & $5.31 \times 10^{-3}$ \\
\hline NEOP & 2,2-DIMETHYLPROPANE (NEO-PENTANE) & $1.32 \times 10^{-4}$ \\
\hline M3HEX & 3-METHYLHEXANE & $5.00 \times 10^{-3}$ \\
\hline NC6H14 & HEXANE (N-HEXANE) & $1.66 \times 10^{-2}$ \\
\hline $\mathrm{NC} 10 \mathrm{H} 22$ & DECANE (N-DECANE) & $2.89 \times 10^{-2}$ \\
\hline HEX2ONE & 2-HEXANONE (METHYL N-BUTYL KETONE) & $4.22 \times 10^{-4}$ \\
\hline CHEX & CYCLOHEXANE & $2.75 \times 10^{-2}$ \\
\hline M2PE & 2-METHYLPENTANE & $1.17 \times 10^{-2}$ \\
\hline ETHGLY & ETHANE-1,2-DIOL (ETHYLENE GLYCOL) & $4.57 \times 10^{-3}$ \\
\hline GLYOX & GLYOXAL & $1.22 \times 10^{-5}$ \\
\hline PROPACID & PROPANOIC ACID & $6.59 \times 10^{-7}$ \\
\hline M3PE & 3-METHYLPENTANE & $7.91 \times 10^{-3}$ \\
\hline MEPROPENE & 2-METHYLPROPENE (1-BUTENE, BUTYLENE) & $2.41 \times 10^{-3}$ \\
\hline $\mathrm{M} 23 \mathrm{C} 4$ & 2,3-DIMETHYLBUTANE & $2.86 \times 10^{-3}$ \\
\hline TPENT2ENE & TRANS-2-PENTENE & $2.90 \times 10^{-3}$ \\
\hline M2HEX & 2-METHYLHEXANE & $5.26 \times 10^{-3}$ \\
\hline ME3BUT1ENE & 3-METHYL-1-BUTENE & $1.65 \times 10^{-3}$ \\
\hline $\mathrm{NC} 8 \mathrm{H} 18$ & OCTANE (N-OCTANE) & $2.15 \times 10^{-2}$ \\
\hline HEX1ENE & 1-HEXENE & $6.55 \times 10^{-4}$ \\
\hline $\mathrm{NC} 9 \mathrm{H} 20$ & NONANE (N-NONANE) & $1.40 \times 10^{-2}$ \\
\hline $\mathrm{C} 4 \mathrm{H} 6$ & 1-3 BUTADIENE & $5.92 \times 10^{-2}$ \\
\hline $\mathrm{NC} 11 \mathrm{H} 24$ & HENDECANE (N-UNDECANE) & $2.33 \times 10^{-2}$ \\
\hline $\mathrm{C} 2 \mathrm{H} 2$ & ETHYNE (ACETYLENE) & $1.65 \times 10^{-2}$ \\
\hline $\mathrm{NC} 12 \mathrm{H} 26$ & DODECANE (N-DODECANE) & $1.11 \times 10^{-2}$ \\
\hline CYHEXOL & CYCLOHEXANOL & $2.78 \times 10^{-4}$ \\
\hline $\mathrm{C} 2 \mathrm{H} 4$ & ETHENE (ETHYLENE) & $3.14 \times 10^{-2}$ \\
\hline DIETETHER & DIETHYL ETHER & $1.30 \times 10^{-4}$ \\
\hline PROPGLY & PROPANE-1,2-DIOL (PROPYLENE GLYCOL) & $9.92 \times 10^{-5}$ \\
\hline EOX2EOL & 2-ETHOXY ETHANOL & $2.95 \times 10^{-3}$ \\
\hline
\end{tabular}


Table 9. Relative emissions factors for individual VOCs as calculated from Eq. (5) in Sect. 3.2

\begin{tabular}{|c|c|c|}
\hline MCM name & species name & emissions ratio \\
\hline $\mathrm{CH} 3 \mathrm{CO} 2 \mathrm{H}$ & ETHANOIC ACID & $4.02 \times 10^{-4}$ \\
\hline IPROACET & I-PROPYL ACETATE & $4.68 \times 10^{-3}$ \\
\hline CBUT2ENE & CIS-2-BUTENE & $4.37 \times 10^{-3}$ \\
\hline BUOX2ETOH & 2-BUTOXY ETHANOL & $5.31 \times 10^{-3}$ \\
\hline TBUT2ENE & TRANS-2-BUTENE & $4.38 \times 10^{-3}$ \\
\hline NPROACET & N-PROPYL ACETATE & $1.58 \times 10^{-3}$ \\
\hline PENT1ENE & 1-PENTENE & $3.38 \times 10^{-3}$ \\
\hline $\mathrm{DMC}$ & DIMETHYL CARBONATE & $6.48 \times 10^{-6}$ \\
\hline CPENT2ENE & CIS-2-PENTENE & $2.86 \times 10^{-3}$ \\
\hline CH2CL2 & $\begin{array}{l}\text { DICHLOROMETHANE } \\
\text { (METHYLENE DICHLORIDE) }\end{array}$ & $1.06 \times 10^{-2}$ \\
\hline ME2BUT1ENE & 2-METHYL-1-BUTENE & $1.36 \times 10^{-3}$ \\
\hline TCE & $\begin{array}{l}\text { TETRA-CHLOROETHENE } \\
\text { (PER-CHLOROETHYLENE) }\end{array}$ & $7.53 \times 10^{-3}$ \\
\hline ME3BUOL & 3-METHYL-1-BUTANOL (I-PENTANOL, I-AMYL ALCOHOL) & $6.75 \times 10^{-9}$ \\
\hline CDICLETH & CIS-1,2-DICHLOROETHENE & $4.49 \times 10^{-5}$ \\
\hline ME2BUT2ENE & 2-METHYL-2-BUTENE & $2.48 \times 10^{-3}$ \\
\hline TOLUENE & METHYLBENZENE (TOLUENE) & $8.37 \times 10^{-2}$ \\
\hline CHEX2ENE & CIS-2-HEXENE & $3.24 \times 10^{-5}$ \\
\hline OXYL & 1,2-DIMETHYL BENZENE (O-XYLENE) & $2.12 \times 10^{-2}$ \\
\hline THEX2ENE & TRANS-2-HEXENE & $3.24 \times 10^{-5}$ \\
\hline EBENZ & ETHYL BENZENE & $2.06 \times 10^{-2}$ \\
\hline $\mathrm{C} 5 \mathrm{H} 8$ & 2-METHYL-1,3-BUTADIENE (ISOPRENE) & $4.26 \times 10^{-6}$ \\
\hline IPBENZ & I-PROPYL BENZENE (CUMENE) & $1.98 \times 10^{-3}$ \\
\hline APINENE & ALPHA-PINENE & $3.67 \times 10^{-4}$ \\
\hline TM135B & 1,3,5-TRIMETHYL BENZENE (MESITELENE) & $6.30 \times 10^{-3}$ \\
\hline MIBKAOH & 4-HYDROXY-4-METHYL-2-PENTANONE & $2.15 \times 10^{-3}$ \\
\hline PETHTOL & $\begin{array}{l}\text { 1-ETHYL 4-METHYL BENZENE } \\
\text { (DIACETONE ALCOHOL) } \\
\text { (P-ETHYL TOLUENE) }\end{array}$ & $6.93 \times 10^{-3}$ \\
\hline $\mathrm{CH} 3 \mathrm{OCH} 3$ & DIMETHYL ETHER & $9.05 \times 10^{-4}$ \\
\hline STYRENE & ETHENYL BENZENE (STYRENE) & $1.42 \times 10^{-3}$ \\
\hline СН3ОСНO & METHYL FORMATE & $3.93 \times 10^{-7}$ \\
\hline DIEK & 3-PENTANONE (DIETHYL KETONE) & $2.86 \times 10^{-4}$ \\
\hline ETHACET & ETHYL ACETATE & $1.43 \times 10^{-2}$ \\
\hline BENZENE & BENZENE & $2.17 \times 10^{-2}$ \\
\hline METHACET & METHYL ACETATE & $1.07 \times 10^{-4}$ \\
\hline BENZAL & BENZENECARBONAL (BENZALDEHYDE) & $8.40 \times 10^{-4}$ \\
\hline DIIPRETHER & DI I-PROPYL ETHER & $2.35 \times 10^{-5}$ \\
\hline MXYL & 1,3-DIMETHYL BENZENE (M-XYLENE) & $3.78 \times 10^{-2}$ \\
\hline MO2EOL & 2-METHOXY ETHANOL & $1.88 \times 10^{-9}$ \\
\hline PXYL & 1,4-DIMETHYL BENZENE (P-XYLENE) & $2.54 \times 10^{-2}$ \\
\hline PR2OHMOX & 1-METHOXY 2-PROPANOL & $1.51 \times 10^{-3}$ \\
\hline PBENZ & N-PROPYL BENZENE & $4.14 \times 10^{-3}$ \\
\hline BOX2PROL & 1-BUTOXY 2-PROPANOL & $3.98 \times 10^{-4}$ \\
\hline TM123B & $\begin{array}{l}\text { 1,2,3-TRIMETHYL BENZENE } \\
\text { (HEMIMELLITENE) }\end{array}$ & $5.50 \times 10^{-3}$ \\
\hline NBUTACET & N-BUTYL ACETATE & $1.21 \times 10^{-2}$ \\
\hline TM124B & $\begin{array}{l}\text { 1,2,4-TRIMETHYL BENZENE } \\
\text { (PSEUDOCUMENE) }\end{array}$ & $1.82 \times 10^{-2}$ \\
\hline SBUTACET & S-BUTYL ACETATE & $5.60 \times 10^{-4}$ \\
\hline OETHTOL & $\begin{array}{l}\text { 1-ETHYL 2-METHYL BENZENE } \\
\text { (O-ETHYL TOLUENE) }\end{array}$ & $4.99 \times 10^{-3}$ \\
\hline $\mathrm{CH} 3 \mathrm{CL}$ & CHLOROMETHANE (METHYL CHLORIDE) & $1.72 \times 10^{-5}$ \\
\hline METHTOL & $\begin{array}{l}\text { 1-ETHYL 3-METHYL BENZENE } \\
\text { (M-ETHYL TOLUENE) }\end{array}$ & $7.92 \times 10^{-3}$ \\
\hline CHCL3 & TRICHLOROMETHANE (CHLOROFORM) & $1.96 \times 10^{-6}$ \\
\hline DIME35EB & $\begin{array}{l}\text { 1,3-DIMETHYL 5-ETHYL BENZENE } \\
\text { (3,5-DIMETHYL ETHYL BENZENE) }\end{array}$ & $1.43 \times 10^{-2}$ \\
\hline CH3CCL3 & 1,1,1-TRICHLOROETHANE & $1.55 \times 10^{-2}$ \\
\hline DIET35TOL & $\begin{array}{l}\text { 1,3-DIETHYL 5-METHYLBENZENE } \\
\text { (METHYL CHLOROFORM) } \\
\text { (3,5-DIETHYL TOLUENE) }\end{array}$ & $2.51 \times 10^{-3}$ \\
\hline TRICLETH & TRI-CHLOROETHENE & $2.10 \times 10^{-2}$ \\
\hline $\mathrm{PHCOOH}$ & BENZOIC ACID (PHENYL CARBOXYLIC ACID) & $1.49 \times 10^{-9}$ \\
\hline TDICLETH & TRANS-1,2-DICHLOROETHENE & $1.48 \times 10^{-5}$ \\
\hline
\end{tabular}


Acknowledgements. The authors would like to thank the NERC for financial support through the URGENT programme, Dick Derwent for allowing the use of the Lagrangian trajectory model and Mike Jenkins and Tamás Turányi for useful discussions.

Edited by: F. J. Dentener

\section{References}

AEAT-ENV: http://www.aeat-env.com

Atkinson, R.: A structure-activity relationship for the estimation of rate constants for the gas-phase reactions of $\mathrm{OH}$ radicals with organic compounds, Int. J. Chem.Kin., 19, 799-828, 1987.

Atkinson, R.: Kinetics and mechanisms of the gas-phase reactions of the hydroxyl radical with organic compounds, J. Phys. Chem. Ref. Data, Monograph 1, 1989.

Atkinson, R.: Gas phase tropospheric chemistry of organic compounds - a review, Atm. Env., 24A, 1-41, 1990.

Atkinson, R.: Gas-Phase tropospheric chemistry of organiccompounds, J. Phys. Chem. Ref. Data, Monograph 2, 1994.

Atkinson, R., Baulch, D. L., Cox, R. A., Hampson, J. A., Kerr, J. A., and Troe, J.: Evaluated kinetic and photochemical data for atmospheric chemistry: supplement IV, Atm. Env., 26, 1187-1230, 1992.

Berzins, M. and Furzland, R. M.: A user's manual for Sprint - A versatile software package for solving systems of algebraic, ordinary and partial differential equations: Part 1 - algebraic and ordinary differential equations, Shell Research Ltd, TNER 85.058, 1985.

Derwent, R. G. and Jenkin, M. E.: Hydrocarbons and long-range transport of ozone and PAN across Europe, Atm. Env., 25A, 1661-1678, 1990.

Derwent, R. G. and Nodop, K.: Long range transport and deposition of acidic nitrogen species in North-West Europe., Nature., 324, 356-358, 1986.

Derwent, R. G., Jenkin, M. E., and Saunders, S. M.: Photochemical ozone creation potentials for a large number of reactive hydrocarbons under European conditions, Atm. Env., 30, 181-199, 1996.

Heard, A., Pilling, M. J., and Tomlin, A. S.: Mechanism reduction techniques applied to tropospheric chemistry, Atm. Env., 32, 1059-1073, 1998.

Hesstvedt, H., Hov, O., and Isaksen, I. S. A.: Quasi-steady state assumption in air pollution modelling, Int. J. Chem. Kinet., 10, 971-994, 1978.

Hough, A. M.: The calculation of photolysis rates for use in global tropospheric modelling studies, AERE Report R-13259 (HMSO), London, 1988.

Jenkin, M., Saunders, S. M., and Pilling, M. J.: The tropospheric degradation of volatile organic compounds :A protocol for mechanism development., Atm. Env., 31, 81-104, 1997.

Jenkin, M. E., Hayman, G. D., Derwent, R. G., Saunders, S. M., Carslaw, N., Pascoe, N., and Pilling, M. J.: Tropospheric chemistry modelling: Improvements to current models and application to policy issues, Report AEAT-4867/20150/R004, 1999.

Jenkin, M. E., Saunders, S. M., Wagner, V., and Pilling, M. J.: Protocol for the development of the Master Chemical Mechanism, MCM v3 (Part B): tropospheric degradation of aromatic volatile organic compounds., Atmos. Chem. Phys., 3, 181-193, 2003, SRef-ID: 1680-7324/acp/2003-3-181.
Kwok, E. S. C. and Atkinson, R.: Estimation Of hydroxyl radical reaction-rate constants for gas-phase organic compounds using a structure-reactivity relationship - an update, Atm. Env., 29, 1685-1695, 1995

Lam, S. H. and Goussis, G. A.: Understanding complex chemical kinetics with computational singular perturbation, 22nd Symp. (Int.) Comb., pp. 931-941, 1988.

Lightfoot, P. D., Cox, R. A., Crowley, J. N., Estriau, M., Hayman, G. D., Jenkin, M. E., Moortgat, G. K., and Zabel, F.: Organic peroxy-radicals - kinetics, spectroscopy and tropospheric chemistry, Atm. Env., 26A, 1805-1964, 1992.

Lorenz, E. N.: On the existence of a slow manifold, J. Atm. Sci, 43, 1547-1557, 1986.

Lowe, R. and Tomlin, A. S.: Low-dimensional manifolds and reduced chemical models for tropospheric chemistry simulations, Atm. Env, 34, 2425-2436, 2000.

Maas, U. and Pope, S. B.: Simplifying chemical kinetics:intrinsic low dimensional manifolds in composition space, Combust. Flame, 88, 239-264, 1992

McRae, G. J., Goodin, W. R., and Seinfeld, J. H.: Development of a second generation mathematical model for urban air pollution - I. Model formation, Atm. Env., 16, 679-696, 1982.

NAEI: 1998 Emissions Inventory aeat/2/env/078 issue 1, 2000.

Peeters, J., Boullart, W., and Van Hoeymissen, J.: Site-specific partial rate constants for $\mathrm{OH}$ addition to alkenes and dienes, Proc. EUROTRAC symp. 1994, Garmisch-Partenkirchen, FRG. April 1994, pp. 110-114, 1994.

Pilling, M. J., Saunders, S., Carslaw, N., Pascoe, S., Jenkin, M., and Derwent, D.: http://www.chem.leeds.ac.uk/Atmospheric/MCM/ mcmproj.html, 1999.

PUMA: http://badc.nerc.ac.uk/data/urgent/Projects-Doc/pumaco. html, 2001.

Roberts, X.: The atmospheric chemistry of organic nitrates, Atm Env., 24A, 243-287, 1990.

Roussel, M. R. and Fraser, S. J.: On the geometry of transient relaxation, J. Chem. Phys., 94, 7106-7113, 1991.

Rudd, H. J.: Emissions of volatile organic compounds from stationary sources in the United Kingdom: Speciation., Report AEA/CS/16419033/REMA-029, 1995.

Saunders, S. M., Jenkin, M. E., Derwent, R. G., and Pilling, M. J.: Protocol for the development of the Master Chemical Mechanism, MCM v3 (Part A): tropospheric degradation of nonaromatic volatile organic compounds, Atmos. Chem. Phys., 3, 161-180, 2003,

SRef-ID: 1680-7324/acp/2003-3-161.

Tomlin, A. S., Pilling, M. J., Turányi, T., Merkin, J. H., and Brindley, J.: Mechanism reduction for the oscillatory oxidation of hydrogen: sensitivity and quasi-steady-state analyses, Combust. Flame, 91, 107-130, 1992.

Tomlin, A. S., Turányi, T., and Pilling, M. J.: Autoignition and low temperature combustion of hydrocarbons, chap. Mathematical tools for construction, investigation and reduction of combustion mechanisms., Elesvier, Amsterdam., 1998.

Tomlin, A. S., Whitehouse, L. E., Lowe, R., and Pilling, M. J.: Low dimensional manifolds in tropospheric chemical systems, Farad. Disc., 120, 125-146, 2001.

Turányi, T.: KINAL: A program package for kinetic analysis of complex reaction mechanisms, Comp. Chem., 14, 253-254, 1990a. 
Turányi, T.: Reduction of large reaction mechanisms, New J. Chem., 14, 795-803, 1990 b.

Turányi, T., Bérces, T., and Vajda, S.: Reaction rate analysis of complex kinetic systems., Int. J. Chem. Kin., 21, 83-99, 1989.

Turányi, T., Tomlin, A. S., and Pilling, M. J.: On the error of the quasi-steady-state approximation, J. Phys. Chem., 97, 163-172, 1993.

Vajda, S., Valkó, P., and Turányi, T.: Principal component analysis of kinetic-models, Int. J. Chem. Kin., 17, 55-81, 1985.
Whitehouse, L. E., Tomlin, A. S., and Pilling, M. J.: Systematic Reduction of Complex Tropospheric Chemical Mechanisms, Part II: Lumping Using a Time-Scale Based Approach, Atmos. Chem. Phys., 4, 2057-2081, 2004,

SRef-ID: 1680-7324/acp/2004-4-2057.

Zeng, G., Pilling, M. J., and Saunders, S. M.: Mechanism reduction for tropospheric chemistry - butane oxidation, J. Chem. Soc. Farad. Trans., 93, 2937-2946, 1997. 